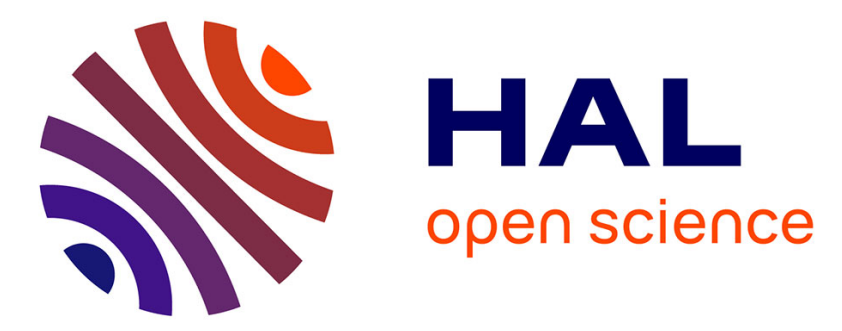

\title{
Novel Fe2TiO5/reduced graphene oxide heterojunction photocatalyst with improved adsorption capacity and visible light photoactivity: experimental and DFT approach
}

Mohamed K. Guediri, Derradji Chebli, Abdallah Bouguettoucha, Riadh Bourzami, Abdeltif Amrane

\section{To cite this version:}

Mohamed K. Guediri, Derradji Chebli, Abdallah Bouguettoucha, Riadh Bourzami, Abdeltif Amrane. Novel Fe2TiO5/reduced graphene oxide heterojunction photocatalyst with improved adsorption capacity and visible light photoactivity: experimental and DFT approach. Environmental Science and Pollution Research, 2021, 28 (7), pp.8507-8519. 10.1007/s11356-020-11221-0 . hal-02996413

\section{HAL Id: hal-02996413 https://hal.science/hal-02996413}

Submitted on 20 Nov 2020

HAL is a multi-disciplinary open access archive for the deposit and dissemination of scientific research documents, whether they are published or not. The documents may come from teaching and research institutions in France or abroad, or from public or private research centers.
L'archive ouverte pluridisciplinaire HAL, est destinée au dépôt et à la diffusion de documents scientifiques de niveau recherche, publiés ou non, émanant des établissements d'enseignement et de recherche français ou étrangers, des laboratoires publics ou privés. 
1 Novel $\mathrm{Fe}_{2} \mathrm{TiO}_{5} /$ reduced graphene oxide heterojunction photocatalyst with

2 improved adsorption capacity and visible light photoactivity: experimental

Mohamed K. GUEDIRI ${ }^{\mathrm{a}}$, Derradji CHEBLI ${ }^{\mathrm{a}}$, Abdallah BOUGUETTOUCHA* ${ }^{\mathrm{a}}$, Riadh

5 BOURZAMI $^{\mathrm{b}}$, Abdeltif AMRANE ${ }^{\mathrm{c}}$

a Département de Génie des Procédés, Laboratoire de Génie des Procédés Chimiques, Faculté de Technologie, Université Ferhat Abbas, Sétif-1, 19000 Sétif, Algeria

Tel. +213 369251 21; Fax: +213 369251 21;

E-mail :derradji_chebli@yahoo.fr;abdallah.bouguettoucha@univ-setif.dz;guedirimedkhalil91@outlook.fr

${ }^{\mathrm{b}}$ Emergent Materials Research unit, Ferhat Abbas University Setif 1, Setif 19000, Algeria

$$
\text { E-mail : riadh_bourzami@hotmail.com }
$$

${ }^{\mathrm{c}}$ Univ Rennes, Ecole Nationale Supérieure de Chimie de Rennes, CNRS, ISCR - UMR6226, F-35000 Rennes, France.E-mail:abdeltif.amrane@univ-rennes1.fr

\section{Abstract}

The design of high efficiency materials is a major challenge for the degradation of organic pollutants. In this work, type II p-n heterojunction photocatalyst $\mathrm{Fe}_{2} \mathrm{TiO}_{5} / \mathrm{rGO}$, with enhanced performance, was successfully prepared through simple process. The $\mathrm{Fe}_{2} \mathrm{TiO}_{5} / \mathrm{rGO}$ composites were prepared by hosting several amounts of reduced Graphene Oxide (rGO) into pseudobrookite nanocrystals $\left(\mathrm{Fe}_{2} \mathrm{TiO}_{5}\right)$ which were priorly synthesized by a solid-state reaction. The morphology and the properties of the as-prepared 
1 composites were characterized trough different techniques. The fixation of rGO sheets on

$2 \mathrm{Fe}_{2} \mathrm{TiO}_{5}$ was proved using the X-Ray Diffraction analysis (XRD). The results for the

3 Scanning Electron Microscope (SEM) analysis showed a good mixing of rGO with

$4 \quad \mathrm{Fe}_{2} \mathrm{TiO}_{5}$. The X-Ray Fluorescence (XRF) confirmed the purity of the pristine $\mathrm{Fe}_{2} \mathrm{TiO}_{5}$.

5 The Dynamic Light Scattering (DLS) illustrated a strong tendency to aggregation.

6 Ultraviolet-Visible Diffuse Reflectance Spectroscopy (UV-Vis DRS) analysis was

7 performed to characterize the electronic aspect as the gap and the Urbach energies.

8 Finally, computational Density Functional Theory DFT calculations were carried out to

9 confirm the experimental results. The adsorptive and photoactivity of $\mathrm{Fe}_{2} \mathrm{TiO}_{5} / \mathrm{rGO}$

10 heterojunction photocatalysts were evaluated by methylene blue (MB) degradation

11 under visible light irradiation. The highest MB degradation rate was achieved for

$12 \mathrm{Fe}_{2} \mathrm{TiO}_{5} / \mathrm{rGO}_{10}$ \% photocatalyst with the highest value of the elimination rate.

Keywords: $\mathrm{Fe}_{2} \mathrm{TiO}_{5}$; reduced graphene oxide; adsorption; photocatalysis; DFT; pollutants elimination. 


\section{Introduction}

Water pollution is caused by various categories of toxic chemical and biological materials, such as organic dyes which are recognized as common pollutants that threaten human health and the environment (Chen et al. 2018). Often, several techniques are used to treat several types of pollutants on the same chain; depending on the quality of water, each method requires a distinct reuse or disposal action plan. Biological, chemical and physical techniques of water remediation are frequently implemented (Ambashta and Sillanpää 2010). The adsorption is the most applied method for the elimination of coloring agents due to its efficiency and ease of use. However, the adsorption process has certain limitations, such as the inability to remove certain elements and the production of secondary wastes which require an additional treatment (Mekhalif et al. 2017). To avoid these drawbacks, the advanced oxidation processes (AOP) have been rapidly expanded and widely considered. Photocatalysis is one of the most effective AOPs in the degradation of organic compounds, the reduction of metal cations or the mixture of the two, which is characterized by low consumption of energy, moderate cost, and strong efficiency of pollutant degradation and mineralization (Elhalil et al. 2017). Adsorption accompanied with the photocatalytic process seems therefore the most appropriate technique for the treatment of water, air and soil (Alves 2019; Inamuddin et al. 2019). The photocatalysis is based on the production of non-selective Reactive Oxidizing Species (ROS) such as hydroxyl $\mathrm{OH}^{\bullet}$, 
superoxide $\mathrm{O}_{2}{ }^{--}$and $\mathrm{H}_{2} \mathrm{O}_{2}$, that allow the oxidation of many organic pollutants. The implementation of Semiconductor materials is of great interest in this process. When the semiconductor is activated by photons, electron-hole pairs are generated by exciting the electrons from the Valence Band (VB) to the Conductive Band (CB), and the migration of the photogenerated electron-holes to the semiconductor surface produces ROS through redox water reactions (Tong et al. 2016). However, the rapid recombination of the photogenerated electron-hole pairs limits the applications of photocatalysis systems in industry, and improving the life time are the major deals of the scientific research ( $\mathrm{Li}$ et al. 2018). Moreover, for implementation in industry, a photocatalyst must fulfill the following conditions: wide absorption in the visible solar spectrum, high charge transport properties; it should also exhibits a high surface/volume ratio, a structural stability (thermal and aqueous) and should be nontoxic, abundant, and cheap (Bassi et al. 2014).

The pseudobrookite $\mathrm{Fe}_{2} \mathrm{TiO}_{5}$ material is an n-type semiconductor (Bassi et al. 2014; Waqas et al. 2017a) and has attracted a growing interest owing to its notable many prospective applications ( $\mathrm{Lv}$ et al. 2017). It has an atomic structure matching that of $\mathrm{TiO}_{2}$ and a band gap energy of about 2.0 to $2.2 \mathrm{eV}$ (depending on the synthesis method). Moreover, the minimal energy of $\mathrm{CB}$ of $\mathrm{Fe}_{2} \mathrm{TiO}_{5}$ is around $-0.7 \mathrm{eV}$ and that of $\mathrm{TiO}_{2}$ is around $-0.5 \mathrm{eV}$; those values lead to a quick charge transfer under light illumination (Waqas et al. 2017a). So, it was investigated as a photocatalyst for use in the visible domain (Bassi et al. 2016; Waqas et al. 2017b; Lv et al. 2017). In parallel, $\mathrm{Fe}_{2} \mathrm{TiO}_{5}$ also drew attentions due to its unique magnetic properties (Enhessari et al. 2014), anisotropic spin-glass behavior at low temperature (Tholence et al. 1986) and conductive properties (Gao et al. 2015). Thus, an alternative potential approach for enhancement of water oxidation consists to develop heterojunctions. In this way, 
heterojunction between $\mathrm{Fe}_{2} \mathrm{TiO}_{5}$ and other semiconductor was studied previously ( $\mathrm{Li}$ et al. 2016; Lin et al. 2016; Waqas et al. 2017a).

In concrete terms, graphene is used thermodynamically in the building of heterojunction photocatalysts susceptible to wide spectrum or in the doping of wide bandgap semiconductors (Zhang et al. 2011; Xie et al. 2013; Li et al. 2018). Owing to high efficiency charge transfer and high-quality heterojunction interfaces and extremely reactive catalyst surfaces (Zhang et al. 2011), graphene is also used kinetically to enhance the efficiency of photocatalysis owing to the high adsorption capacity of organic / inorganic contaminants (Pu et al. 2017). For those arguments, the combination of graphene with various semiconductors was suggested as a promising research route. For example, the formation of $\mathrm{p}$-n heterojunctions between $\mathrm{KTaO}_{3}$ nanocubes and rGO (reduced Graphene Oxide) sheets leads to $\mathrm{KTaO}_{3} / \mathrm{rGO}$ composites, which have shown a significant improvement in the photocatalytic performance of phenol degradation under visible light irradiation that can be attributed to the role of graphene photosensitizer (Bajorowicz et al. 2015). A second example can be given by $\mathrm{LaFeO}_{3} / \mathrm{rGO}$ nanocomposites, which showed to be an effective photocatalyst for the degradation of methyl orange dye under visible light irradiation (Kumar et al. 2017).

This research work aims at synthesizing a new heterojunction $\mathrm{Fe}_{2} \mathrm{TiO}_{5} / \mathrm{rGO}$ nanocomposite photocatalyst. The composite structure and morphology, electronic, and absorption properties were systematically studied and further linked with the photocatalytic studies by investigated in the Methylene Blue (MB) degradation as a model organic pollutant. As far as we know, the bulk of the literature works focuses only on the experimental or the theoretical study search separately. Hence, aspects related to the mechanism of reactions remain unclear. For this, the aim, several experimental characterizations, and theoretical computational based on density functional theory (DFT) were employed to achieve a clearer picture. 


\section{Experimental}

\subsection{Materials and methods}

\subsubsection{Materials}

Natural graphite (99.8\%, -325 mesh, Alfa Aesar), potassium permanganate $\mathrm{KMnO}_{4}$ (99\%, Panreac), hydrogen peroxide $\mathrm{H}_{2} \mathrm{O}_{2}$ (30\%, Schrlau), sulfuric acid $\mathrm{H}_{2} \mathrm{SO}_{4}(98 \%$, Schrlau), hydrochloric acid $\mathrm{HCl}$ (37\%, Schrlau), potassium nitrate $\mathrm{KNO}_{3}(\geq 99.0 \%$, analytical grade) and barium chloride $\mathrm{BaCl}_{2} \cdot 2 \mathrm{H}_{2} \mathrm{O}(99.9 \%$, Biochem.) were used as precursors or solvent for the preparation of rGO. Anatase titanium oxide $\mathrm{TiO}_{2}(>99 \%$, 325 mesh, Sigma Aldrich), iron oxide $\mathrm{Fe}_{2} \mathrm{O}_{3}$ (99\%, Chempur), ethanol and acetone (Rectapur) were used as precursors or solvents for the preparation of $\mathrm{Fe}_{2} \mathrm{TiO}_{5}$. Methylene blue (MB) (Sigma Aldrich) was used as target molecule for the photocatalytic studies. All chemicals were of analytical reagent level and were used as obtained without further purification.

\subsubsection{Characterization techniques}

X-Ray Diffraction XRD patterns were carried out in the range from $2 \theta=4^{\circ}$ to $85^{\circ}$, with an angular step about $0.0167^{\circ}$ and 6.985 s per step, using a Siemens D5000 diffractometer equipped with $\mathrm{Cu}$ anticathode, operated at $45 \mathrm{KV}$ and $35 \mathrm{~mA}$. Optical transmission and absorption spectra were performed in Ultraviolet-Visible Diffuse Reflection Spectroscopy (UV-Vis-DRS) spectrometer, Shimadzu (UV-3600 spectrophotometer with a Harrick Praying Mantis accessory). The morphology was performed with Scanning Electron Microscopy (SEM) type FEI QUANTA 250 FEG (FEI, Hillsboro, OR, USA), with $10 \mathrm{KV}$ as the acceleration voltage. Hydrodynamic diameter was measured using Dynamic Light Scattering (DLS) of the type Horiba 
Patrica LA960, equipped with capillary cell. The photocatalytic studies performed using the Shimadzu $1700 \mathrm{UV}$-Vis spectrophotometer to determine the concentration of $\mathrm{MB}$; the spectra were recorded between 200 and $800 \mathrm{~nm}$ and the kinetic curves were plotted for absorption at $\lambda_{\max }=664 \mathrm{~nm}$ of the MB.

\subsubsection{Preparation methods}

\subsubsection{Preparation of Graphene Oxide (GO)}

Graphene Oxide (GO) was synthesized according to the modified Hummers method (Dhinesh Kumar et al. 2017; Atout et al. 2017). In a typical synthesis, $5 \mathrm{~g}$ of powder graphite and $2.5 \mathrm{~g}$ of potassium nitrate $\mathrm{K}\left(\mathrm{NO}_{3}\right)$ were added to $115 \mathrm{~mL}$ of $98 \%$ sulfuric acid $\mathrm{H}_{2} \mathrm{SO}_{4}$ and mixed with constant stirring; the mixture temperature was kept below $10{ }^{\circ} \mathrm{C}$ using an ice bath. $15 \mathrm{~g}$ of potassium permanganate $\mathrm{KMnO}_{4}$ was then slowly added to the suspension and the stirring persisted for 2 hours. At the end, the temperature was increased to $35^{\circ} \mathrm{C}$ and the mixture was kept at this temperature for another 45 minutes. Additionally, $230 \mathrm{~mL}$ of distilled water was added to the paste, the temperature was increased to $98{ }^{\circ} \mathrm{C}$ and the reaction was retained for 45 minutes. Finally, the resulted suspension was further diluted with addition of $350 \mathrm{~mL}$ of warm distilled water, and then treated with $15 \mathrm{~mL}$ of $\mathrm{H}_{2} \mathrm{O}_{2}$ (30\%) solution to reduce the residual permanganate; the addition of $\mathrm{H}_{2} \mathrm{O}_{2}$ resulted in yellow color, indicating high level of oxidation and the manganese dioxide swing to colorless soluble manganese sulfate. The suspension was washed five times with $5 \% \mathrm{HCl}$ aqueous solution using a centrifuge (6000 rpm for 5 minutes) until the complete removal of $\mathrm{SO}_{4}{ }^{-2}$. The removal of $\mathrm{SO}_{4}{ }^{-2}$ was detected by addition of barium chloride, where the presence of sulfate ion induced a white precipitate when barium chloride was added to the supernatant (Emiru and Ayele 2017). The mixture was then repeatedly centrifuged and washed with de- 
ionized water until the supernatant's $\mathrm{pH}$ was neutral. The material was finally dried for 72 hours at $40{ }^{\circ} \mathrm{C}$ giving brown-black sample.

\subsubsection{Preparation of $\mathrm{Fe}_{2} \mathrm{TiO}_{5}$ nanocrystal using solid state reaction}

Equimolar quantities of $\mathrm{Fe}_{2} \mathrm{O}_{3}$ and $\mathrm{TiO}_{2}$ were placed as a lubricant in $50 \mathrm{ml}$ of acetone. The solution was put for $1 \mathrm{~h}$ in an ultrasonic bath. The powder was dried at $80{ }^{\circ} \mathrm{C}$ and placed in a crucible and air-heated at $900{ }^{\circ} \mathrm{C}$ for 24 hours (Huerta-Flores et al. 2015).

\subsubsection{Preparation of $\mathrm{Fe}_{2} \mathrm{TiO}_{5} / \mathrm{rGO}_{\mathrm{x}}$ photocatalysts}

The preparation of $\mathrm{Fe}_{2} \mathrm{TiO}_{5} / \mathrm{rGO}_{\mathrm{x}}$ photocatalysts with different weight ratios 5, 10 and 15 wt.\% of rGO to $\mathrm{Fe}_{2} \mathrm{TiO}_{5}$ were prepared via hydrothermal method (Bajorowicz et al.). $200 \mathrm{mg}$ of $\mathrm{Fe}_{2} \mathrm{TiO}_{5}$ powder and appropriate mass percent of $\mathrm{GO}$ were dispersed in solution of $\mathrm{H}_{2} \mathrm{O}(40 \mathrm{~mL})$ and ethanol $(20 \mathrm{~mL})$; the obtained mixture was treated for 2 hours in an ultrasonic bath and stirred for another 2 hours to obtain homogeneous suspension. The suspension was transferred to Teflon sealed autoclave and kept for 12 hours at $120{ }^{\circ} \mathrm{C}$. The resulting product was washed four times with distilled water and ethanol using a centrifuge (6000 rpm for 5 minutes) and dried in an oven at $60{ }^{\circ} \mathrm{C}$ for 24 hours.

\subsection{Kinetics of adsorption}

The adsorption kinetics represent an important step in the study of an adsorption process, allowing to determine the time needed to achieve the adsorption equilibrium (Chebli et al. 2015). The procedure was carried out in the dark and at room temperature as follows: $0.25 \mathrm{~g} / \mathrm{l}$ of $\mathrm{Fe}_{2} \mathrm{TiO}_{5} / \mathrm{rGO}_{\mathrm{x}}(\mathrm{x}=0,5,10$ and 15\%) were dispersed in a $200 \mathrm{ml}$ solution of $\mathrm{MB}$ at a concentration of $10 \mathrm{mg} / \mathrm{L}$, the mixture was rigorously stirred. To follow the evolution of the adsorbed quantity ( $\left.Q_{\text {ads }}\right)$, samples were taken at time 
intervals of $10 \mathrm{~min}$ until equilibrium was obtained. The elimination yield was calculated according to Eq.1:

$\mathrm{R}(\%)=\frac{\left(C_{0}-C_{e}\right)}{C_{0}} \times 100$

Where $\mathrm{R}$ is the percentage of $\mathrm{MB}$ fixed on the adsorbent, $\mathrm{C}_{0}$ is the initial concentration of the MB solution (mg/L) and Ce is the residual concentration of the MB solution at equilibrium (mg/L).

\subsection{Equilibrium modeling}

The adsorption dynamics allow to determine the residence time of the adsorbed molecules on the interface of the solid solution. Among the several kinetic models implemented for this purpose (Chebli et al. 2015; Bouguettoucha et al. 2016; Guediri et al. 2020), three models were considered in this work: pseudo-first-order, pseudosecond order and pseudo $\mathrm{n}^{\text {th }}$ order. The correlation coefficient $\mathrm{R}^{2}$ allows to estimate the conformity of the experimental outcomes with those of the modeling.

\subsubsection{Pseudo First Order model (PFO)}

The PFO kinetic model can be related to the adsorption at the solid/liquid interface; this model is based on the adsorption capacity (Chebli et al. 2015; Bouguettoucha et al. 2016; Guediri et al. 2020) and described by the Eq.2:

$\frac{d Q_{t}}{d t}=k_{1}\left(Q_{e}-Q_{t}\right)$

Where $\mathrm{Q}_{\mathrm{e}}(\mathrm{mg} / \mathrm{g})$ and $\mathrm{Q}_{\mathrm{t}}(\mathrm{mg} / \mathrm{g})$ refer to the quantity of dye adsorbed at equilibrium and at $\mathrm{t}(\mathrm{min})$ respectively, $\mathrm{k}_{1}\left(\mathrm{~min}^{-1}\right)$ is the constant of equilibrium rate. 
The solution of the differential equation Eq.2 which took into consideration the boundary conditions $\mathrm{t}=0$ to $\mathrm{t}=\mathrm{t}$ and $\mathrm{Q}_{\mathrm{t}}=0$ to $\mathrm{Q}_{\mathrm{t}}$ gives Eq.3:

$Q_{t}=Q_{e}\left(1-e^{-K_{1} t}\right)$

\subsubsection{Pseudo Second Order model (PSO)}

The PSO model is applicable to a wider time interval, usually the entire adsorption process (Chebli et al. 2015; Bouguettoucha et al. 2016; Guediri et al. 2020); this model is governed by Eq.4:

$Q_{t}=\left(\frac{k_{2} Q_{e}{ }^{2} t}{k_{2} Q_{e} t+1}\right)$

Where $\mathrm{k}_{2}$ (g.mg $\mathrm{min}^{-1}$ ) is the equilibrium rate constant of the PSO model.

\subsubsection{Pseudo $\mathbf{n}^{\text {th }}$ Order $\left(\operatorname{Pn}^{\text {th }} O\right)$}

The general equation without pre-set order to a fixed value can be written as Eq.5 (Chebli et al. 2015; Bouguettoucha et al. 2016; Guediri et al. 2020):

$\frac{d Q_{t}}{d t}=K_{n}\left(Q_{e}-Q_{t}\right)^{n}$ Eq.5

The solution of the differential equation Eq.2 which took into consideration the boundary conditions gives Eq.6:

$Q_{t}=Q_{e}\left(1-\frac{1}{\left[1+(n-1) K_{n} t Q_{e}^{(n-1)}\right]^{\frac{1}{n-1}}}\right)$ Eq.6

\subsection{Adsorption mechanism}

\subsubsection{Boyd and Webber Model (pore-diffusion model)}


Currently, the models of Boyd and Webber are widely used to study the adsorption mechanism (Hameed and El-Khaiary 2008; Viegas et al. 2014). The Boyd's model determines if the primary resistance to mass transfer is in the thin film (boundary layer) surrounding the adsorbent particle or in the diffusion resistance within the pores. This model is described by the following relation:

$F=\frac{Q_{t}}{Q_{e}}=1-\frac{6}{\pi^{2}} \sum_{n=1}^{\infty} \frac{1}{n^{2}} \exp \left(-n^{2} B t\right)$

Where $\mathrm{F}$ is a fractional equilibrium at different times, $\mathrm{t}$, and $\mathrm{Bt}$ is a function of $\mathrm{F}$.

It is not possible to calculate B values for each adsorbed fraction from Eq.7. The following approximations were obtained by implementing the Fourier transformation and then integration:

for $\mathrm{F}>0.85$

$$
B t=-0,4977-\operatorname{Ln}(1-F)
$$

for $\mathrm{F}<0.85$

$$
B t=\left(\sqrt{\pi}-\sqrt{\pi-\left(\frac{\pi^{2} F}{3}\right)}\right)^{2}
$$

They could be used to forecast the mechanism of adsorption using Eq.6 and Eq.7. This can be accomplished by plotting Bt against time. If the plot is linear and goes through the origin, then the rate of mass transfer is governed by the pore diffusion (Dural et al. 2011). If the plot is nonlinear or linear but does not pass through the origin, the adsorption rate is controlled by film-diffusion or chemical reaction.

On the other hand, the pore-diffusion model of Webber is obtained from the second law of diffusion of Fick. The parameter for pore diffusion, $\mathrm{k}_{\mathrm{i}}\left(\mathrm{mg} / \mathrm{g} \mathrm{min}^{0.5}\right)$ is described by:

$Q_{t}=k_{i} \cdot t^{0,5}$ 
Where $\mathrm{Q}_{\mathrm{t}}$ is the adsorbed quantity (mg/g) at a given time t. From Eq.12, if porediffusion is the rate-limiting step, then a $Q_{t}$ plot against $t^{0.5}$ must offer a straight line with a slope equal to $\mathrm{k}_{\mathrm{i}}$ and an intercept equivalent to zero.

\subsection{Photocatalytic tests}

The photocatalytic experiments were performed using a batch photoreactor at room temperature. A visible LED spotlight (LED Projector 50W Ultra-fin SMD - IP66) with luminous flow $=4000 \mathrm{~lm}$, placed at $30 \mathrm{~mm}$ above an open-air double-walled beaker of $200 \mathrm{ml}$ and a cooling water jacket which maintains the reaction temperature at $(20 \pm$ 2) ${ }^{\circ} \mathrm{C}$ with exposed surface to LED light of $32.17 \mathrm{~cm}^{2}$. Due to its simple accessibility and its wide industrial use, MB was selected as the model molecule. The procedure was performed as follows: $0.25 \mathrm{~g} / \mathrm{l} \mathrm{mg}$ of $\mathrm{Fe}_{2} \mathrm{TiO}_{5} / \mathrm{rGO}_{\mathrm{x}}(\mathrm{x}=0,5,10$ and 15\%) were dispersed in $200 \mathrm{ml}$ of aqueous solution of $\mathrm{MB}$ (10 mg/L). Firstly, the solution was stirred in the dark for 120 min to achieve the adsorption-desorption equilibrium. After 120 minutes, the LED lamp was switched on and each 20 minutes, $1 \mathrm{ml}$ of the suspension was removed (dilutions $\times 5$ ) and centrifuged instantly to separate the catalyst from the solution, and then, the solution was analyzed by UV-Vis spectroscopy. All photocatalytic experiments were conducted in duplicate to guarantee photocatalyst photostability.

\subsection{Computational Details}

The aim of the DFT calculation was to explore the impact of electronic corrections on the electronic structure characteristics of the pseudobrookite $\mathrm{Fe}_{2} \mathrm{TiO}_{5}$, and then compare the theoretical results with the experimental ones. The calculations are performed within the framework of the local density approximation (GGA) and 
$(\mathrm{LDA}+\mathrm{U})$ by using the Cambridge Serial Total Energy Package (CASTEP) based on the plane-wave pseudopotential DFT methods with the Perdew-Burke-Ernzerhof (PBE) approximation for the exchange correlation functional. A previous paper used the local spin density approximation Hubbard U (LSDA++U $(U=4))$ approach with the CA-PZ (Jin and Zhou 2013). In this work, the same parameters were also considered for the GGA method: plane wave-based cut-off energy was set at $1000 \mathrm{eV}$ and k-points grid sampling were set at $7 * 7 * 3$ for the Brillouin zone. For the parameters of convergence, maximum force tolerance was set at $0.03 \mathrm{eV} / \mathrm{nm}$, maximum stress component was set at $0.05 \mathrm{GPa}$ and total energy tolerance at $1.0 * 10-5 \mathrm{eV} /$ atom.

\section{Results and discussion}

\subsection{Structural analysis}

Figure 1 shows the XRD patterns of $\mathrm{Fe}_{2} \mathrm{TiO}_{5} / \mathrm{rGO}_{\mathrm{x}}(\mathrm{x}=0,5,10$ and 15\%). Several diffraction peaks are observed at angular positions: $2 \theta=18.14^{\circ}, 25.57^{\circ}, 32.57^{\circ}$, $36.61^{\circ}, 37.37^{\circ}, 40.58^{\circ}, 41.09^{\circ}, 46.01^{\circ}, 48.83^{\circ}, 55.22^{\circ}, 56.15^{\circ}$ and $59.68^{\circ}$; these peaks are identified according to the JCPDS card (96-200-2303) as respectively (0 2 0), (1 1

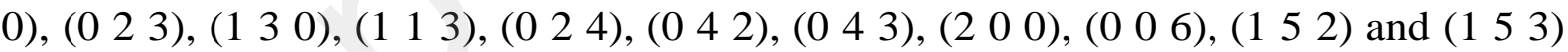
Bragg's planes of the $\mathrm{Fe}_{2} \mathrm{TiO}_{5}$ pseudobrookite structure, in an orthorhombic system. It can be seen that more $\mathrm{x}$ is important more the pattern appears noisy, indicating the presence of amorphous phase in the rGO sheets. Moreover, no new peak is observed for $\mathrm{Fe}_{2} \mathrm{TiO}_{5} / \mathrm{rGO}_{5 \%}$ in comparison with $\mathrm{Fe}_{2} \mathrm{TiO}_{5}$, proving that for small ratio of graphene the crystalline structure is conserved. Above $x=5 \%$, some new peaks appear and are more intense when $\mathrm{x}$ increases, showing a partial transition of the 
pseudobrokite crystalline phase; these new peaks are related to the reduction of $\mathrm{Fe}_{2} \mathrm{TiO}_{5}$ during the fixation of rGO sheets, leading to precursors of $\mathrm{Fe}_{2} \mathrm{O}_{3}$ and $\mathrm{TiO}_{2}$. Furthermore, the diffraction peaks shift to the small angles when $\mathrm{x}$ increases, which means that the crystal is stressed when the rGO sheets are inserted on the surface of $\mathrm{Fe}_{2} \mathrm{TiO}_{5}$. The characteristic crystalline parameters (a, b and c) are illustrated in Table 1, the average grain seize (D), micro-constraint $(\varepsilon \%)$ and dislocation density $(\delta)$, are calculated using the relations (i), (ii) (Langford and Wilson 1978; Sugapriya et al. 2013), (iii) and (iv) (Yousaf et al. 2019) respectively:

(i) $\quad 2 \mathrm{~d}_{\mathrm{hkl}} \sin \theta=\mathrm{n} \lambda$ and $\mathrm{d}_{h k l}=\frac{1}{\sqrt{\frac{\mathrm{h}^{2}}{\mathrm{a}^{2}}+\frac{\mathrm{k}^{2}}{b^{2}}+\frac{l^{2}}{c^{2}}}}$

(ii) $\quad \mathrm{D}=\frac{\mathrm{K} \lambda}{\beta \cos \theta}$

(iii) $\quad \varepsilon \%=\frac{\beta}{4 \tan \theta}$

(iv) $\quad \delta=\frac{1}{D^{2}}$

Where: $d_{h k l}$ is the interreticular spacing, $K=0.94, \lambda=1.5406 \AA$ is $\mathrm{K} \alpha 1 \mathrm{X}$-ray wavelength, $\beta$ is the width at half-height and $\theta$ is the angle of diffraction.

It is clearly seen that the fixation of graphene sheets on $\mathrm{Fe}_{2} \mathrm{TiO}_{5}$ at the microscopic scale increases the lattice parameters, evidently accompanied with an increase of the micro-constraints and at the macroscopic scale reduces significantly the grain seize and induces strong structural defects estimated by an increase of the dislocation density. In comparison with $\mathrm{XRD}$ results, for a high ratio $\mathrm{x}$, the defects reduce partially the crystalline structure of $\mathrm{Fe}_{2} \mathrm{TiO}_{5}$.

\subsection{XRF analysis}


In view of confirming the purity of the synthetized $\mathrm{Fe}_{2} \mathrm{TiO}_{5}$, optical spectroscopy was investigated; XRF analysis proves the presence of $\mathrm{O}, \mathrm{Fe}$ and $\mathrm{Ti}$ elements with different weight percent 37.95\%, 43.2\% and 18.85\% (wt.\%), respectively (Figure 2). These

results are close to the theoretical weight percent given by an ideal unit cell of pseudobrokite $\mathrm{Fe}_{2} \mathrm{TiO}_{5}, \mathrm{O}(33.40 \%)$, Fe (46.62 \%) and $\mathrm{Ti}(19.98 \%)$, confirming the high purity of the compound. The empiric formula can be written as $\mathrm{Fe}_{1.85} \mathrm{Ti}_{0.95} \mathrm{O}_{5.66}$, and is considered thereafter.

\subsection{SEM images}

Figure 3 shows SEM images of $\mathrm{Fe}_{2} \mathrm{TiO}_{5} / \mathrm{rGO}_{\mathrm{x}}$ composite; the top images are captured at strong zoom (x20000) and illustrate that the nanocrystals have different sizes with elongated rhombohedric forms. Bottom images are carried out with weak zoom (x500) and prove that the $\mathrm{Fe}_{2} \mathrm{TiO}_{5}$ nanocrystals are uniformly scattered on the graphene sheets. These observations confirm the formation of the heterojunction of $\mathrm{Fe}_{2} \mathrm{TiO}_{5} / \mathrm{rGO}_{\mathrm{x}}$

\subsection{DLS analysis}

The adsorption and the photocatalytic activities are influenced by the external surface of the nanoparticules and their surface state; and the effective surface exposed to the external medium is the surface of the aggregated particles. Furthermore, the aggregation of transition metal oxides in aqueous solution is well known and wellstudied (Jassby et al. 2012; Melcher et al. 2017). For this purpose, the sample $\mathrm{Fe}_{2} \mathrm{TiO}_{5}$ was characterized by DLS. Figure 4 shows the hydrodynamic diameter of the aggregated nanoparticles in distilled water suspension, and the experimental data was fitted with a Gaussian function. 
The fitted curve indicates the formation of different size of aggregated particles; the average seize value of hydrodynamic diameter is about $752.4 \mu \mathrm{m}$ and the width at half height of the fitted curve is about $333.4 \mu \mathrm{m}$, showing a strong tendency to aggregate of the $\mathrm{Fe}_{2} \mathrm{TiO}_{5}$ particles. The experimental data also shows a shoulder at low values of the hydrodynamic diameter, which can be related to unaggregated particles.

\subsection{Electronic structure and optical properties}

\subsubsection{Band structure}

For the theoretical calculation of the band structure, both LSDA and GGA were used and the results of the band gaps are compared to the experimental values (Table 2). The figure 5 shows the band structures calculated by GGA of the $\mathrm{Fe}_{2} \mathrm{TiO}_{5}$ compounds at the equilibrium lattice parameters along the highest symmetry direction in the Brillouin zone. The separation of the bands exists, and the Fermi level can be located at the band gap, which indicates the semi-conductivity character of $\mathrm{Fe}_{2} \mathrm{TiO}_{5}$. The maximum $\mathrm{VB}$ and minimum $\mathrm{CB}$ are not located at the same Brillouin area point, indicating that the gap is indirect. Moreover, the $\mathrm{Fe}_{2} \mathrm{TiO}_{5}$ compound with pseudobrookite crystalline phase is a paramagnet semiconductor; its magnetic moment is principally centered on the Fe (III) ions, with less contribution of the Ti and O ions that are magnetized via super-exchange interactions. The effective magnetic moment of $\mathrm{Fe}_{2} \mathrm{TiO}_{5}$ is determined and found to be $3.80 \mu_{\mathrm{B}} / \mathrm{Fe}$ (Jin and Zhou 2013). This magnetic moment of the semiconductor split the levels of the band structure, forming two possible band structures (i) alpha electronic stat channel and (ii) beta electronic stat channel. The value of the band gap for the alpha channel calculated by LSDA (U = 
4) is about $1.81 \mathrm{eV}$ (Jin and Zhou 2013); while the gap value calculated by GGA is about $1.88 \mathrm{eV}$, which is the closest to the experimental value.

\subsubsection{UV-Vis-DRS}

For the experimental quantification of the electronic properties, namely the gap energy and the Urbach energy, UV-Vis-DRS spectroscopy is a suitable tool. The spectra shown in Figure 6 (b) correspond to $\mathrm{Fe}_{2} \mathrm{TiO}_{5} / \mathrm{rGO}_{\mathrm{x}}(\mathrm{x}=$ 0, 5, 10 and 15\%). The lines prove that the composites are transparent in the visible range beyond the wavelength $\lambda$ $=600 \mathrm{~nm}$, and show also a strong and large absorption band in the UV and in the visible near the UV regions, most likely due to transitions from the VB to the CB. This band is confirmed by the theoretical calculation using GGA calculation and the obtained theoretical spectrum is shown in Figure 6 (a). The bump around $550 \mathrm{~nm}$ can be attributed to the spin-flip d-d transition (Marusak et al. 1980; Sherman and Waite 1985); this weak band is observed as a shoulder on the theoretical spectrum. To quantify $E_{g}$, the absorption coefficients 'F(R)' must be deduced from the reflectance curves 'R', according to the Kubelka-Munk formula (Simmons 1975; Burgeth and Kisch 2002; Kortüm 2012) :

$$
F(\mathrm{R})=\frac{(1-\mathrm{R})^{2}}{2 \mathrm{R}}
$$

The band gap ' $E_{\mathrm{g}}$ ' is estimated through Tauc plot on the linear part of $(\alpha . h v)^{\mathrm{n}} \propto$ (hv$E_{g}$ ), where $n=1 / 2$ for indirect band gap (insert of Figure 6 ), and $n=2$ for direct gap; these optical transitions are respectively due to transitions from $\mathrm{O} 2 \mathrm{p}$ to Fe3d orbitals and from O2p to Ti3d orbitals. The evaluated band gap energies are summarized in table 2 . 
The Urbach energy $E_{u}$ is calculated by the relation Eq.14 ([CSL STYLE ERROR: reference with no printed form.]), where $\mathrm{E}_{0}$ and $\alpha_{0}$ are constants relative to the studied compound:

$F(R)=\alpha_{0} \exp \left(\frac{\mathrm{hv}-\mathrm{E}_{0}}{\mathrm{E}_{\mathrm{u}}}\right)$

' $E_{U}$ ' is estimated through the plot of $\ln [F(R)] \propto h v$ and it is evaluated from the slope of the linear part: $\ln [F(R)] \propto\left(h v-E_{0}\right)$ (insert of Figure 6). Table 2 sums up the values.

$\mathrm{E}_{\mathrm{U}}$ characterizes the change in the electronic band structure caused by different origins (vacant or interstitial sites, lattice strain, dislocation...). These various origins generate additional states within the band gap close to HOMO and LUMO levels, and can be seen as tails of $\mathrm{CB}$ and $\mathrm{VB}, \mathrm{E}_{\mathrm{U}}$ is roughly equal to the average width of tails (Choudhury et al. 2013). From the table 2, the deposit of rGO sheets on $\mathrm{Fe}_{2} \mathrm{TiO}_{5}$ induces an increase of the Urbach energy. Both XRD and UV-Vis-DRS analyses confirm therefore that the deposit of rGO induces stress and defects within the $\mathrm{Fe}_{2} \mathrm{TiO}_{5}$ nanocrystals.

Moreover, the decrease of $\mathrm{E}_{\mathrm{g}}$ by adding rGO sheets shifts the Fermi level. The shift of Fermi level strengthens the migration of photogenerated electrons and represses the electron-hole recombination, which let expect an amelioration of the photocatalytic activity.

\subsection{Kinetic of adsorption}

Figure 7 shows time-courses of experimental and fitted kinetic curves of $\mathrm{MB}$ adsorption. It is well seen that the equilibrium time was about 120 minutes. Furthermore, due to the high specific surface area of rGO sheets, the adsorption of MB 
was significantly improved (from $Q_{a d s}=2.68 \mathrm{mg} / \mathrm{g}$ to $Q_{a d s}=16.26 \mathrm{mg} / \mathrm{g}$ ) for increasing values of $\mathrm{x}$.

The constant rate $\mathrm{K}$, the theoretical maximum adsorbed quantities $\mathrm{Q}_{\mathrm{e}}$ and the correlation coefficients $\mathrm{R}^{2}$ of fit, given by modeling using PFO, PSO and $\mathrm{Pn}^{\text {th }} \mathrm{O}$ models are included in the Table 3.

From Table 3, the adsorbed quantities Qads calculated by the Pseudo-First Order (PFO) model were fairly far from the experimental values; while the Pseudo-Second Order (PSO) model led to closer $\mathrm{Q}_{\text {ads }}$ values. To assess for the accuracy of the fit, the correlation coefficients $\mathrm{R}^{2}$ is the most appropriate factor; it was found between [0.8750.959] and [0.935-0.990] for PFO, PSO models; while the $\mathrm{Pn}^{\text {th }} \mathrm{O}$ model led to better results, with $\mathrm{R}^{2}$ values in the range [0.973-0.998], and the order for this last model was between 0.119 and 0.425 .

In an attempt to determine the rate controlling step involved in the adsorption of MB on the synthesized composites, the kinetic data were further analyzed using the Boyd and Webber models. Figure 8 (a) Shows Boyd plots for the first $70 \mathrm{~min}$ for MB adsorption. The plots indicate a linear section, which do not cross the origin at the beginning of adsorption. This implies that adsorption does not follow Eq.8 and Eq.9 and therefore does not regulates the adsorption rate during the initial period. This demonstrates that during this period, chemical reaction or film diffusion regulates the adsorption rate.

Figure 8 (b) shows a pore diffusion plots of MB adsorption obtained by the Webber model. It is evidently seen that the plots are multi-linear, having at least three linear sections. The regression findings are seen in Table 4. For various multilinear plots in Figure 8 (b), the regression results of the first linear section give intercept values that differ significantly from zero. These intercept values corroborate the conclusion from the Boyd plots that pore diffusion at this early point does not control the adsorption. It 
is therefore verified that the first linear segment represents film-diffusion (or chemical reaction).

\subsection{Photocatalytic activity study}

The overall elimination of $\mathrm{BM}$ is shown in figure 9. We see that $\mathrm{BM}$ elimination increases with increasing $\mathrm{rGO}$ content for $\mathrm{Fe}_{2} \mathrm{TiO}_{5} / \mathrm{rGO}_{\mathrm{x}}$ composite (with $\mathrm{x}=0,5,10$ and 15 wt.\%) by weight with a yield of $\mathrm{R}=31.39 \%$ to $42.19 \%$ respectively. This elimination is due to the strong adsorption of BM by the rGO following the increase of the interfacial surface developed by the increase of the rGO content in the composite $\mathrm{Fe}_{2} \mathrm{TiO}_{5} / \mathrm{rGO}_{\mathrm{x}}$. This can be clarified in two ways: (i) in dark, by the adsorption phenomena principally of MB on rGO sheets due to its height specific surface, (ii) after saturation of adsorption and under visible light, electron-hole pairs generated within $\mathrm{Fe}_{2} \mathrm{TiO}_{5}$ can oxidize MB via photocatalysis and also, tend to be transferred to graphene sheets and works as the receiver, extending the lifetime of the charge carrier. It is worth noting that the concentration of MB shows no noticeable difference in the absence of Fe2TiO5 / rGOx, indicating that MB cannot be degraded by photolysis. Therefore, any change in the MB concentration can be attributed to the photocatalytic process. The photocatalytic part of the kinetic curves was fitted with an exponential function, leading to the following values of the rate constants $K^{*} 10^{-4}=1.61,5.61$, 15.10, and $4.91 \mathrm{~min}^{-1}$ for the $\mathrm{Fe}_{2} \mathrm{TiO}_{5} / \mathrm{rGO}_{\mathrm{x}}$ composite (with $\mathrm{x}=0,5,10$ and 15 wt.\%) respectively. The heterojunction composite having the ratio $\mathrm{x}=10 \%$ presents a weak modification of the crystalline structure and it has the highest value of the rate constant. This result can be explained by lower access to the photocatalytic sites of $\mathrm{Fe}_{2} \mathrm{TiO}_{5}$ owing to the over-crowding of rGO sheets when the composite heterojunction has more than $10 \%$ of $x$ (Atout et al. 2017). In addition, other factors are also known as 
the fundamental operating parameters in heterogeneous photocatalysis such as the initial pollutant concentration, catalyst load, $\mathrm{pH}$ of the solution, and the intensity of light, which can affect the effectiveness of the photocatalytic process, and it's been discussed in detail by (Favier et al. 2015, 2016; Ounnar et al. 2016b, a). The effect of these factors on the photocatalytic degradation rate of most organic compounds is evident according to last works.

\section{Proposed mechanism}

A preliminary mechanism for the photocatalytic process is proposed based on the above results and illustrated in figure 10. Upon LED light excitation, electron-hole pairs generate within the semiconductor $\mathrm{Fe}_{2} \mathrm{TiO}_{5}$, these photogenerated electrons tend to be transferred to graphene sheets, graphene accepts the electrons generated during photocatalysis and has worked beneficially a the receiver, This extends the lifetime of the charge carrier and is then scavenged by dissolved oxygen, thus facilitating the separation of the hole-electron. Furthermore, the $\mathrm{O}_{2} / \cdot \mathrm{O}_{2}{ }^{-}$reduction potential is $-0.16 \mathrm{~V}$ (vs. NHE), which is very near to the rGO Fermi level ( 0 V vs. NHE) potential. Consequently, the electron on the rGO surface could be captured by $\mathrm{O}_{2}$ to form ' $\mathrm{O}^{-}$and further, generate $\mathrm{H}_{2} \mathrm{O}_{2}$. The rGO also played a role in scavenging the photoexcited electron from $\mathrm{Fe}_{2} \mathrm{TiO}_{5}$, resulting in the abundance of photoexcited electrons on the rGO surface to promote the formation of ${ }^{\circ} \mathrm{O}_{2}{ }^{-}$and $\mathrm{H}_{2} \mathrm{O}_{2}$ for $\mathrm{MB}$ degradation. Therefore, in the present nano-heterostructure of $\mathrm{Fe}_{2} \mathrm{TiO}_{5} / \mathrm{rGO}$, the scavenged electrons on rGO as well as the radical anion process dominated the degradation mechanism of $\mathrm{MB}$. In the meantime, the holes leaving the semiconductor $\mathrm{Fe}_{2} \mathrm{TiO}_{5}$ from the $\mathrm{VB}$ either react to form hydroxyl radicals with adsorbed water or directly oxidize MB.

The graphene in the composites facilitates the separation of charge, restrains the hole-electron recombination, and gives a large surface/interface for heterogeneous connection reactions. 
Furthermore, graphene oxide is a mixture of hybridized carbon atoms Sp2 and Sp3 with very high oxygen bonding on hybrid carbon Sp3. Oxygen atoms have a higher electronegativity than carbon atoms and thus graphene oxide becomes a p-type semiconductor material where its conduction band is the orbital antibonding $\pi^{*}$ and its valence band is basically the orbital Op2. By removing most of the oxygen-containing functional groups from the GO surface using the hydrothermal route, the reduced graphene oxide was obtained. However, the p-type behavior of the rGO was caused by oxygen remaining on the carbon surface. A p-n junction composite photocatalyst can be obtained when combining rGO sheets with n-type $\mathrm{Fe}_{2} \mathrm{TiO}_{5}$ semiconductors. There are some advantages of forming p-n heterostructures, such as (a) more effective charge separation; (b) fast charge transfer to the catalyst; (c) longer charge carrier life; and (d) separation of locally incompatible nano-space reduction and oxidation reactions. As a result, the enhancement of the photocatalytic activity of $\mathrm{Fe}_{2} \mathrm{TiO}_{5} / \mathrm{rGO}$ composites under visible light could be ascribed to the formation of p-n heterojunctions between $\mathrm{Fe}_{2} \mathrm{TiO}_{5}$ and rGO sheets. It should be noted that the electronic interactions and charge balance between graphene and semiconductor result in a shift in the Fermi level and decrease the semiconductor's CB potential (Figure 10) $\mathrm{E}_{\text {gap }}=2.06 \mathrm{eV}$ to $\mathrm{E}_{\text {gap }}=1.95 \mathrm{eV}$. Thus, the negative shift in $\mathrm{Fe}_{2} \mathrm{TiO}_{5} / \mathrm{rGO}$ Fermi level and the high migration of photoinduced electrons efficiency effectively suppress the recombination of the charge, resulting in increased photocatalytic activity. 


\section{Conclusions}

The $\mathrm{Fe}_{2} \mathrm{TiO}_{5}$ nanocrystals were successfully synthesized and were used with rGO to form heterojunction composites. The XRD analysis proved that the $\mathrm{Fe}_{2} \mathrm{TiO}_{5}$ nanocrystals have a pseudobrookite crystalline structure; this structure is conserved after the deposition of rGO, although the crystalline seize decreases. Furthermore, SEM images proved the formation of the heterojunction and the good mixing of rGO with $\mathrm{Fe}_{2} \mathrm{TiO}_{5}$. The experimental gap value was given by the UV-Vis-DRS spectroscopy and was found to be about $2.06 \mathrm{eV}$, while the gap value given by DFT was about $1.81 \mathrm{eV}$ and 1.88 using LSDA+U and GGA calculations respectively; the gap value was reduced when the quantity of rGO increased.

Moreover, the adsorption kinetic curves showed that the amount of MB adsorbed increased with the increase of the rGO amount. The fit of the kinetic curves proved that the pseudo $\mathrm{n}^{\text {th }}$ order model is adequate, and the modeling of the experimental results 
illustrated that the adsorption mechanism is guided by film-diffusion and/or chemical reaction. Furthermore, the photocatalytic study showed that all synthetized compounds have an impact on the degradation of the MB under visible light; the junction with rGO sheets improves considerably the photocatalytic performances and the best results were obtained using the $\mathrm{Fe}_{2} \mathrm{TiO}_{5} / \mathrm{rGO}_{10 \%}$ composite.

\section{References}

Alves AK (2019) Nanophotocatalysts for Fuel Production. In: Inamuddin, Ahamed MI, Asiri AM, Lichtfouse E (eds) Nanophotocatalysis and Environmental Applications : Energy Conversion and Chemical Transformations. Springer International Publishing, Cham, pp 1-15

Ambashta RD, Sillanpää M (2010) Water purification using magnetic assistance: a review. Journal of hazardous materials 180:38-49

Atout H, Álvarez MG, Chebli D, et al (2017) Enhanced photocatalytic degradation of methylene blue: Preparation of TiO2/reduced graphene oxide nanocomposites by direct sol-gel and hydrothermal methods. Materials Research Bulletin 95:578-587. https://doi.org/10.1016/j.materresbull.2017.08.029 
Bajorowicz B, Reszczyńska J, Lisowski W, et al (2015) Perovskite-type KTaO3-reduced graphene oxide hybrid with improved visible light photocatalytic activity. RSC Adv 5:91315-91325. https://doi.org/10.1039/C5RA18124K

Bajorowicz B, Reszczyńska J, Lisowski W, et al Perovskite-type KTaO3-reduced graphene oxide hybrid with improved visible light photocatalytic activity. 11

Bassi PS, Antony RP, Boix PP, et al (2016) Crystalline Fe2O3/Fe2TiO5 heterojunction nanorods with efficient charge separation and hole injection as photoanode for solar water oxidation. Nano Energy 22:310-318

Bassi PS, Chiam SY, Barber J, Wong LH (2014) Hydrothermal grown nanoporous iron based titanate, Fe2TiO5 for light driven water splitting. ACS applied materials \& interfaces $6: 22490-22495$

Bouguettoucha A, Reffas A, Chebli D, et al (2016) Novel activated carbon prepared from an agricultural waste, Stipa tenacissima, based on $\mathrm{ZnCl} 2$ activation—characterization and application to the removal of methylene blue. Desalination and Water Treatment $57: 24056-24069$

Burgeth G, Kisch H (2002) Photocatalytic and photoelectrochemical properties of titaniachloroplatinate(IV). Coordination Chemistry Reviews 230:41-47. https://doi.org/10.1016/S0010-8545 (02)00095-4

Chebli D, Bouguettoucha A, Mekhalef T, et al (2015) Valorization of an agricultural waste, Stipa tenassicima fibers, by biosorption of an anionic azo dye, Congo red. Desalination and Water Treatment 54:245-254 
Chen S, Zhou M, Li T, Cao W (2018) Synthesis of Ag-loaded Sb2WO6 microsphere with enhanced photocatalytic ability for organic dyes degradations under different light irradiations. Journal of Molecular Liquids 272:27-36

Choudhury B, Dey M, Choudhury A (2013) Defect generation, d-d transition, and band gap reduction in Cu-doped $\mathrm{TiO} 2$ nanoparticles. Int Nano Lett 3:25. https://doi.org/10.1186/2228-5326-3-25

Dhinesh Kumar R, Thangappan R, Jayavel R (2017) Facile Preparation of LaFeO3/rGO Nanocomposites with Enhanced Visible Light Photocatalytic Activity. Journal of Inorganic and Organometallic Polymers and Materials 27:892-900. https://doi.org/10.1007/s10904-017-0534-8

Dural MU, Cavas L, Papageorgiou SK, Katsaros FK (2011) Methylene blue adsorption on activated carbon prepared from Posidonia oceanica (L.) dead leaves: Kinetics and equilibrium studies. Chemical Engineering Journal 168:77-85. https://doi.org/10.1016/j.cej.2010.12.038

Elhalil A, Elmoubarki R, Sadiq M, et al (2017) Enhanced photocatalytic degradation of caffeine as a model pharmaceutical pollutant by Ag-ZnO-Al2O3 nanocomposite. DESALINATION AND WATER TREATMENT 94:254-262. https://doi.org/10.5004/dwt.2017.21587

Emiru TF, Ayele DW (2017) Controlled synthesis, characterization and reduction of graphene oxide: A convenient method for large scale production. Egyptian Journal of Basic and Applied Sciences 4:74-79. https://doi.org/10.1016/j.ejbas.2016.11.002 
Enhessari M, Razi MK, Etemad L, et al (2014) Structural, optical and magnetic properties of the Fe2TiO5 nanopowders. Journal of Experimental Nanoscience 9:167-176. https://doi.org/10.1080/17458080.2011.649432

Favier L, Harja M, Simion AI, et al (2016) Advanced oxidation process for the removal of chlorinated phenols in aqueous suspensions. Journal of Environmental Protection and Ecology 17:1132-1141

Favier L, Simion AI, Rusu L, et al (2015) REMOVAL OF AN ORGANIC REFRACTORY COMPOUND BY PHOTOCATALYSIS IN BATCH REACTOR - KINETIC STUDIES. Environmental Engineering and Management Journal 14:1327-1338. https://doi.org/10.30638/eemj.2015.144

Gao XM, Li MW, Hou YL, Wang CY (2015) Characterisation of Fe2TiO5 nanocrystallites synthesised via homogeneous precipitation. Materials Research Innovations 19:1-6

Guediri A, Bouguettoucha A, Chebli D, et al (2020) Molecular dynamic simulation and DFT computational studies on the adsorption performances of methylene blue in aqueous solutions by orange peel-modified phosphoric acid. Journal of Molecular Structure 1202:127290. https://doi.org/10.1016/j.molstruc.2019.127290

Hameed BH, El-Khaiary MI (2008) Malachite green adsorption by rattan sawdust: Isotherm, kinetic and mechanism modeling. Journal of Hazardous Materials 159:574-579

Huerta-Flores AM, Torres-Martínez LM, Sánchez-Martínez D, Zarazúa-Morín ME (2015) SrZrO3 powders: alternative synthesis, characterization and application as photocatalysts for hydrogen evolution from water splitting. Fuel 158:66-71 
Inamuddin, Ahamed MI, Asiri AM, Lichtfouse E (2019) Nanophotocatalysis and environmental applications: energy conversion and chemical transformations

Jassby D, Farner Budarz J, Wiesner M (2012) Impact of Aggregate Size and Structure on the Photocatalytic Properties of $\mathrm{TiO} 2$ and $\mathrm{ZnO}$ Nanoparticles. Environmental Science \& Technology 46:6934-6941. https://doi.org/10.1021/es202009h

Jin L, Zhou C (2013) Electronic structures and optic properties of Fe2TiO5 using LSDA+ U approach. Progress in Natural Science: Materials International 23:413-419

Kortüm G (2012) Reflectance Spectroscopy: Principles, Methods, Applications. Springer Science \& Business Media

Kumar RD, Thangappan R, Jayavel R (2017) Facile Preparation of LaFeO 3/rGO Nanocomposites with Enhanced Visible Light Photocatalytic Activity. Journal of Inorganic and Organometallic Polymers and Materials 27:892-900

Langford JI, Wilson AJC (1978) Scherrer after sixty years: A survey and some new results in the determination of crystallite size. J Appl Cryst, J Appl Crystallogr 11:102-113. https://doi.org/10.1107/S0021889878012844

Li J, Han M, Guo Y, et al (2016) Fabrication of FeVO4/Fe2TiO5 composite catalyst and photocatalytic removal of norfloxacin. Chemical Engineering Journal 298:300-308

Li X, Shen R, Ma S, et al (2018) Graphene-based heterojunction photocatalysts. Applied Surface Science 430:53-107

Lin Y-G, Hsu Y-K, Lin Y-C, Chen Y-C (2016) Electrodeposited Fe2TiO5 nanostructures for photoelectrochemical oxidation of water. Electrochimica Acta 213:898-903 
Lv X, Nie K, Lan H, et al (2017) Fe2TiO5-incorporated hematite with surface P-modification for high-efficiency solar water splitting. Nano Energy 32:526-532. https://doi.org/10.1016/j.nanoen.2017.01.001

Marusak LA, Messier R, White WB (1980) Optical absorption spectrum of hematite, $\alpha \mathrm{Fe} 2 \mathrm{O} 3$ near IR to UV. Journal of Physics and Chemistry of Solids 41:981-984

Mekhalif T, Guediri K, Reffas A, et al (2017) Effect of acid and alkali treatments of a forest waste, Pinus brutia cones, on adsorption efficiency of methyl green. Journal of Dispersion Science and Technology 38:463-471

Melcher J, Barth N, Schilde C, et al (2017) Influence of TiO2 agglomerate and aggregate sizes on photocatalytic activity. J Mater Sci 52:1047-1056. https://doi.org/10.1007/s10853-016-0400-z

Ounnar A, Bouzaza A, Favier L, Bentahar F (2016a) Macrolide antibiotics removal using a circulating TiO2-coated paper photoreactor: parametric study and hydrodynamic flow characterization. Water Science and Technology 73:2627-2637. https://doi.org/10.2166/wst.2016.096

Ounnar A, Favier L, Bouzaza A, et al (2016b) Kinetic study of spiramycin removal from aqueous solution using heterogeneous photocatalysis. Kinetics and Catalysis 57:200206. https://doi.org/10.1134/S0023158416020087

Pu Y-C, Chou H-Y, Kuo W-S, et al (2017) Interfacial charge carrier dynamics of cuprous oxide-reduced graphene oxide (Cu2O-rGO) nanoheterostructures and their related visible-light-driven photocatalysis. Applied Catalysis B: Environmental 204:21-32 
Sherman DM, Waite TD (1985) Electronic spectra of Fe3+ oxides and oxide hydroxides in the near IR to near UV. American Mineralogist 70:1262-1269

Simmons EL (1975) Diffuse reflectance spectroscopy: a comparison of the theories. Appl Opt $14: 1380-1386$

Sugapriya S, Sriram R, Lakshmi S (2013) Effect of annealing on TiO2 nanoparticles. Optik International Journal for Light and Electron Optics 124:4971-4975. https://doi.org/10.1016/j.ijleo.2013.03.040

Tholence JL, Yeshurun Y, Kjems JK, Wanklyn B (1986) Spin dynamics and low temperature properties of the anisotropic spin glass Fe2TiO5. Journal of Magnetism and Magnetic Materials 54-57:203-204. https://doi.org/10.1016/0304-8853(86)90551-2

Tong T, Zhang H, Chen J, et al (2016) The photocatalysis of BiFeO3 disks under visible light irradiation. Catalysis Communications 87:23-26

Viegas RMC, Campinas M, Costa H, Rosa MJ (2014) How do the HSDM and Boyd's model compare for estimating intraparticle diffusion coefficients in adsorption processes. Adsorption 20:737-746. https://doi.org/10.1007/s10450-014-9617-9

Waqas M, Iqbal S, Bahadur A, et al (2017a) Designing of a spatially separated hetero-junction pseudobrookite (Fe2TiO5-TiO2) yolk-shell hollow spheres as efficient photocatalyst for water oxidation reaction. Applied Catalysis B: Environmental 219:30-35

Waqas M, Wei Y, Mao D, et al (2017b) Multi-shelled TiO2/Fe2TiO5 heterostructured hollow microspheres for enhanced solar water oxidation. Nano Research 10:3920-3928 
Xie G, Zhang K, Guo B, et al (2013) Graphene-Based Materials for Hydrogen Generation from Light-Driven Water Splitting. Advanced Materials 25:3820-3839. https://doi.org/10.1002/adma.201301207

Yousaf S, Kousar T, Taj MB, et al (2019) Synthesis and characterization of double heterojunction-graphene nano-hybrids for photocatalytic applications. Ceramics International

Zhang J, Xiong Z, Zhao XS (2011) Graphene-metal-oxide composites for the degradation of dyes under visible light irradiation. Journal of Materials Chemistry 21:3634-3640

The Physics of Semiconductors - An Introduction Including | Marius Grundmann | Springer 


\section{Figures Caption}

Figure 1: $\mathrm{XRD}$ patterns of $\mathrm{Fe}_{2} \mathrm{TiO}_{5} / \mathrm{rGO}_{\mathrm{x}}(\mathrm{x}=0,5,10$ and $15 \%)$, normalized by the highest intensity to 1

Figure 2: The XRF spectrum of FTO obtained using solid state reaction.

Figure 3: SEM images, top images strong zoom x20000 and bottom images weak zoom x500 of (a) $x=0$, (b) $x=5$, (c) $x=10$ and (d) $x=15 \%$ ) (f) rGO.

Figure 4: Hydrodynamic diameter of $\mathrm{Fe}_{2} \mathrm{TiO}_{5}$ in $\mathrm{H}_{2} \mathrm{O}$ suspension.

Figure 5: Energy band structures of alpha (blue line) and beta spin channel (red line) of $\mathrm{Fe}_{2} \mathrm{TiO}_{5}$ along the high symmetry direction in the Brillouin zone.

Figure 6: $\mathrm{UV}$-Visible spectra of $\mathrm{Fe}_{2} \mathrm{TiO}_{5} / \mathrm{rGO}_{\mathrm{x}}(\mathrm{x}=0,5,10$ and 15\%). The insert figure: variation of the band gap $E_{\mathrm{g}}$ according to Kubelka-Munk method and variation of Urbach energy $E_{U}$. All spectra are normalized to 1 by the maximum of absorbance.

Figure 7: Adsorption kinetic curves of $\mathrm{BM}$ on $\mathrm{Fe}_{2} \mathrm{TiO}_{5} / \mathrm{rGO}_{\mathrm{x}}$ composites $\left(\mathrm{C}_{\text {catalyst }}=0.25 \mathrm{~g} / \mathrm{l}\right.$ , $\mathrm{C}_{\mathrm{MB}}=10 \mathrm{mg} / \mathrm{l}$, and $\mathrm{Vol}_{\text {solution }}=200 \mathrm{ml}$ ).

Figure 8: Adsorption of $\mathrm{MB}$ on $\mathrm{Fe}_{2} \mathrm{TiO}_{5} / \mathrm{rGO}_{\mathrm{x}}(\mathrm{x}=0,5,10$ and 15\%) (a) Boyd plots (b) pore-diffusion plots.

Figure 9: Photodegradation of $\mathrm{BM}$ dye $\left(\mathrm{C}_{\text {catalyst }}=0.25 \mathrm{~g} / \mathrm{l}, \mathrm{C}_{\mathrm{MB}}=10 \mathrm{mg} / \mathrm{l}\right.$, and $\mathrm{Vol}_{\text {solution }}=$ $200 \mathrm{ml})$

Figure 10: Schematic illustration of the photocatalytic mechanism of $\mathrm{Fe}_{2} \mathrm{TiO}_{5} / \mathrm{rGO}_{\mathrm{x}}$ composite. 
Figure 1

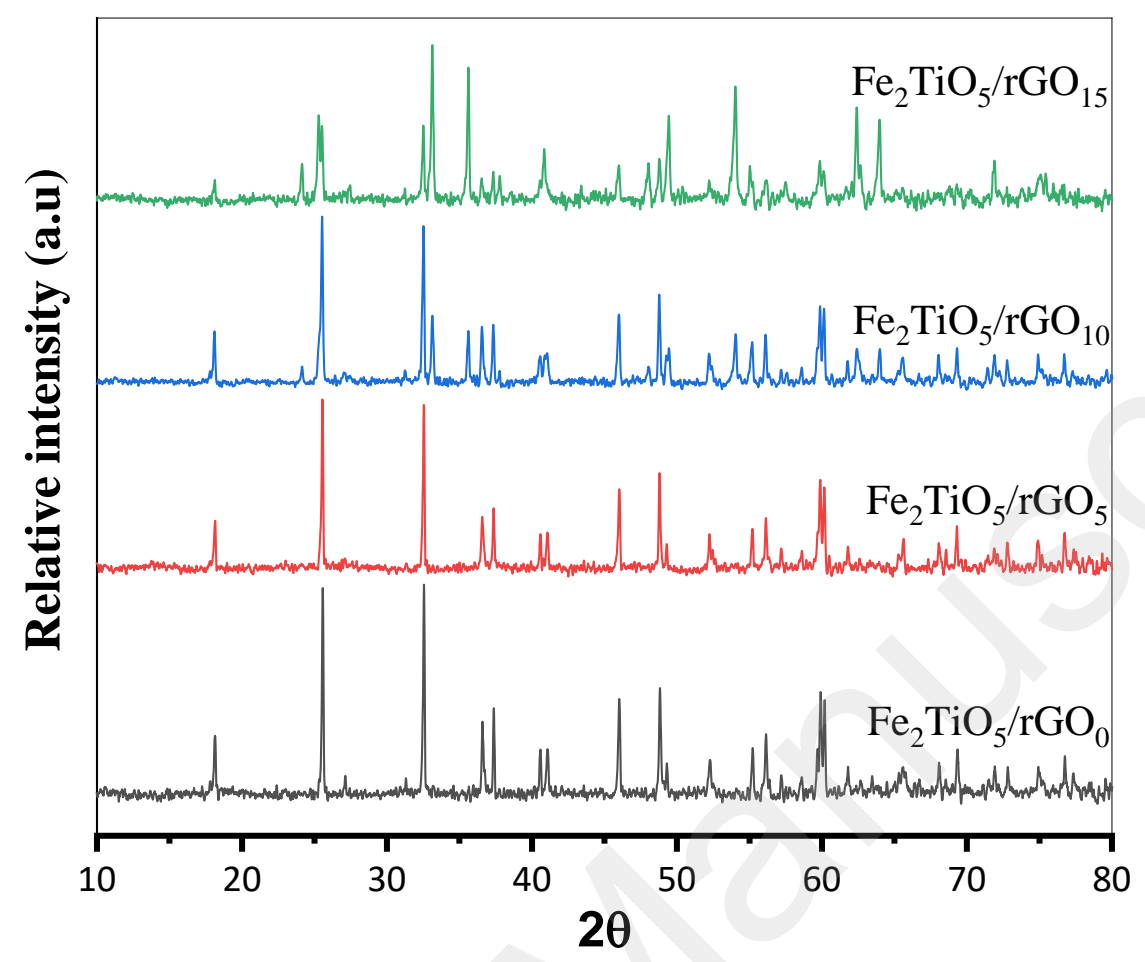


Figure 2

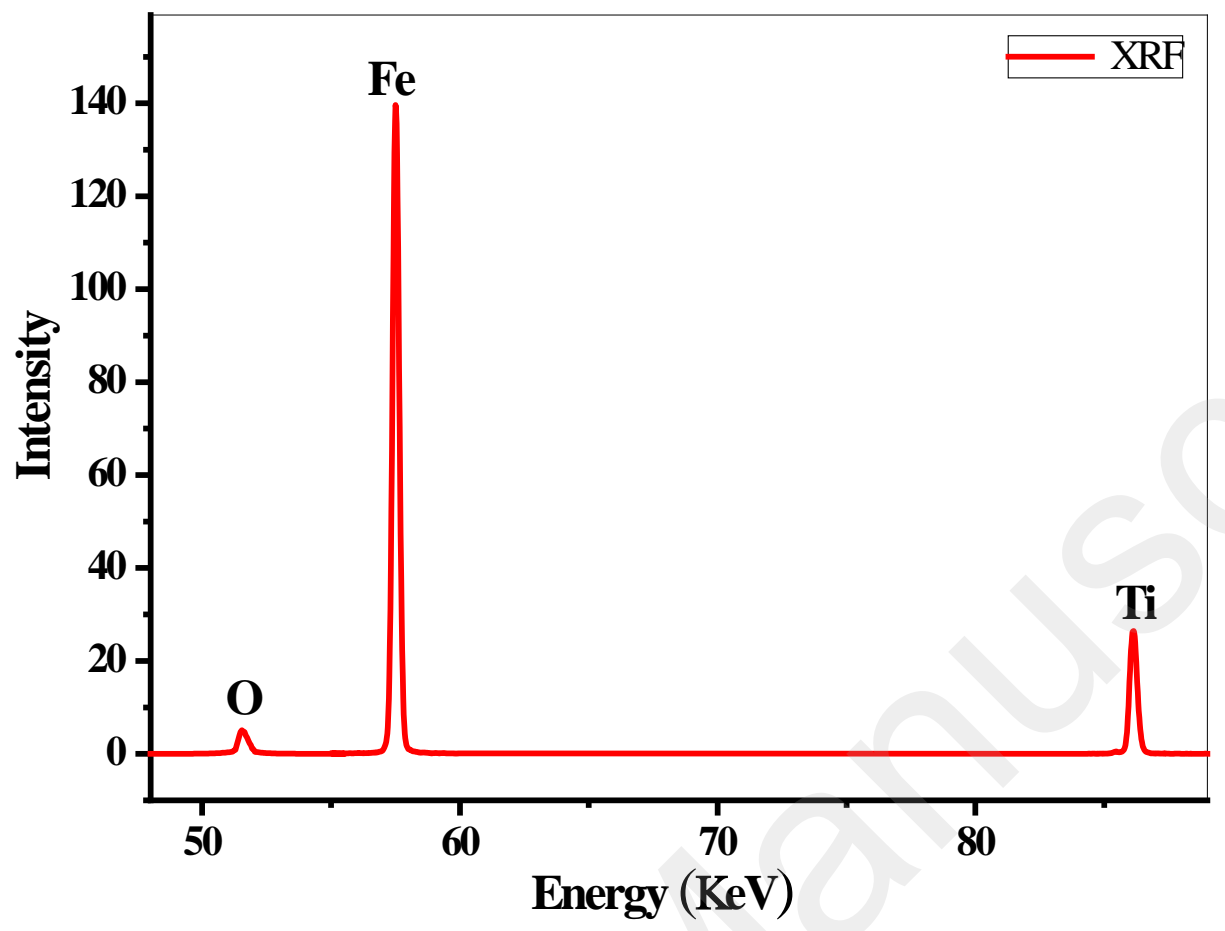


Figure 3
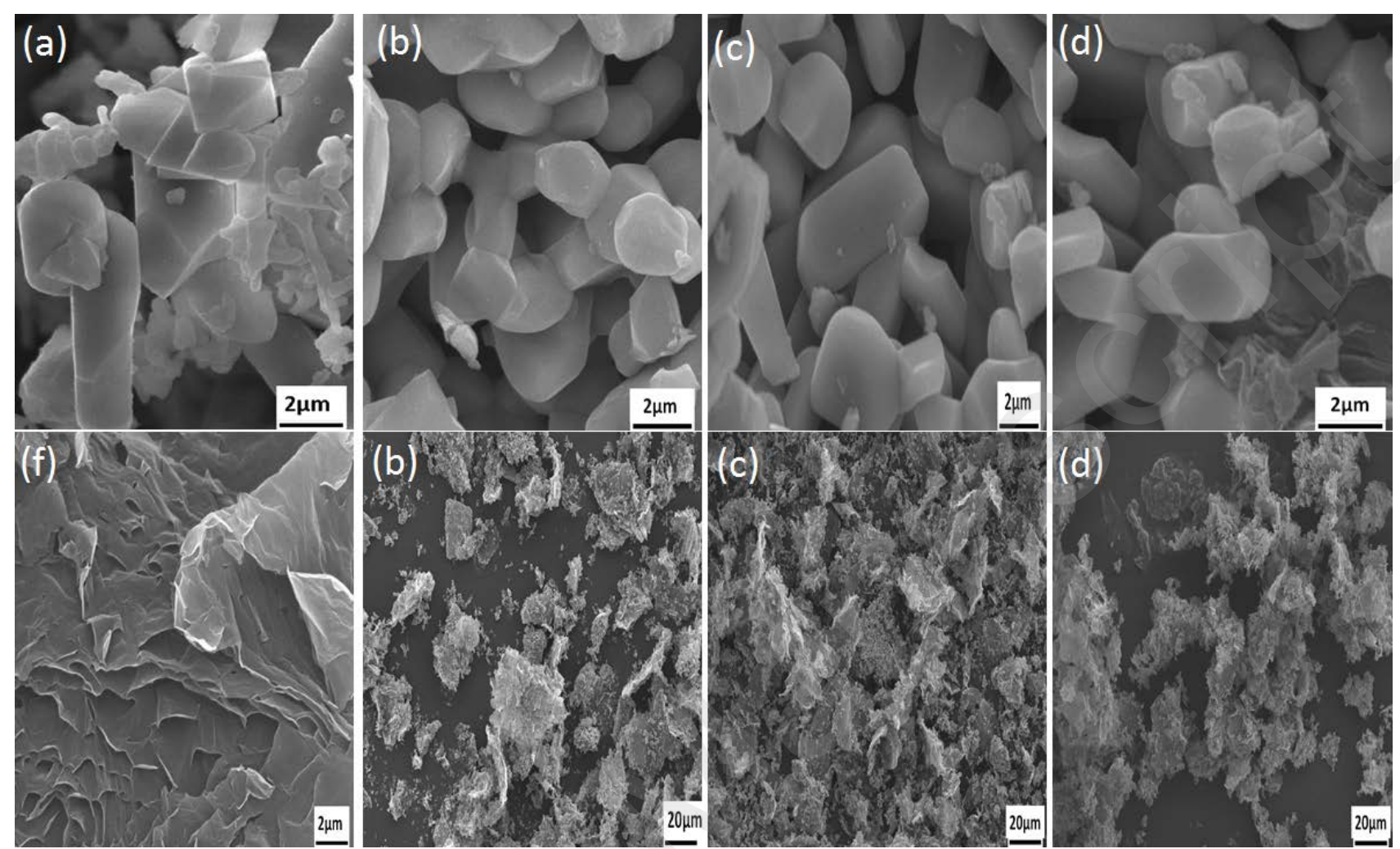
Figure 4

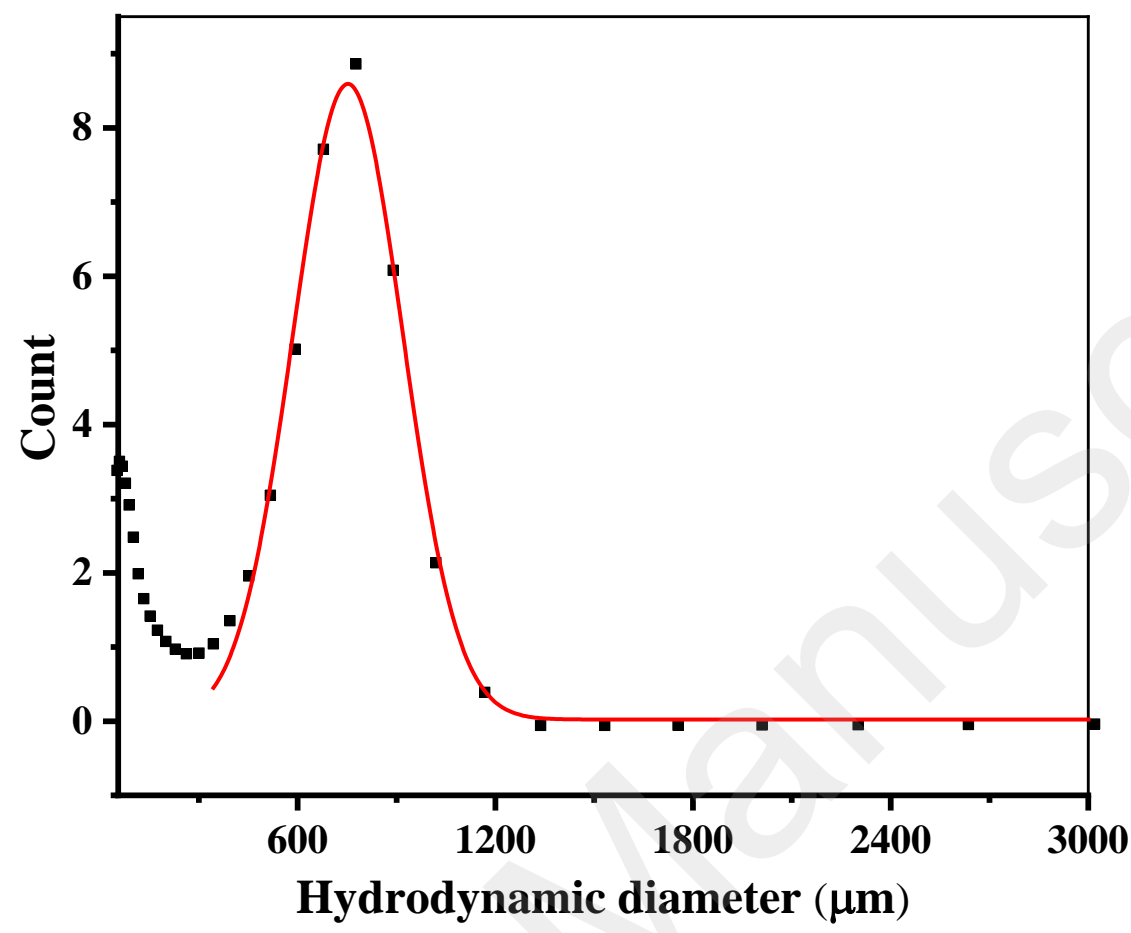


Figure 5
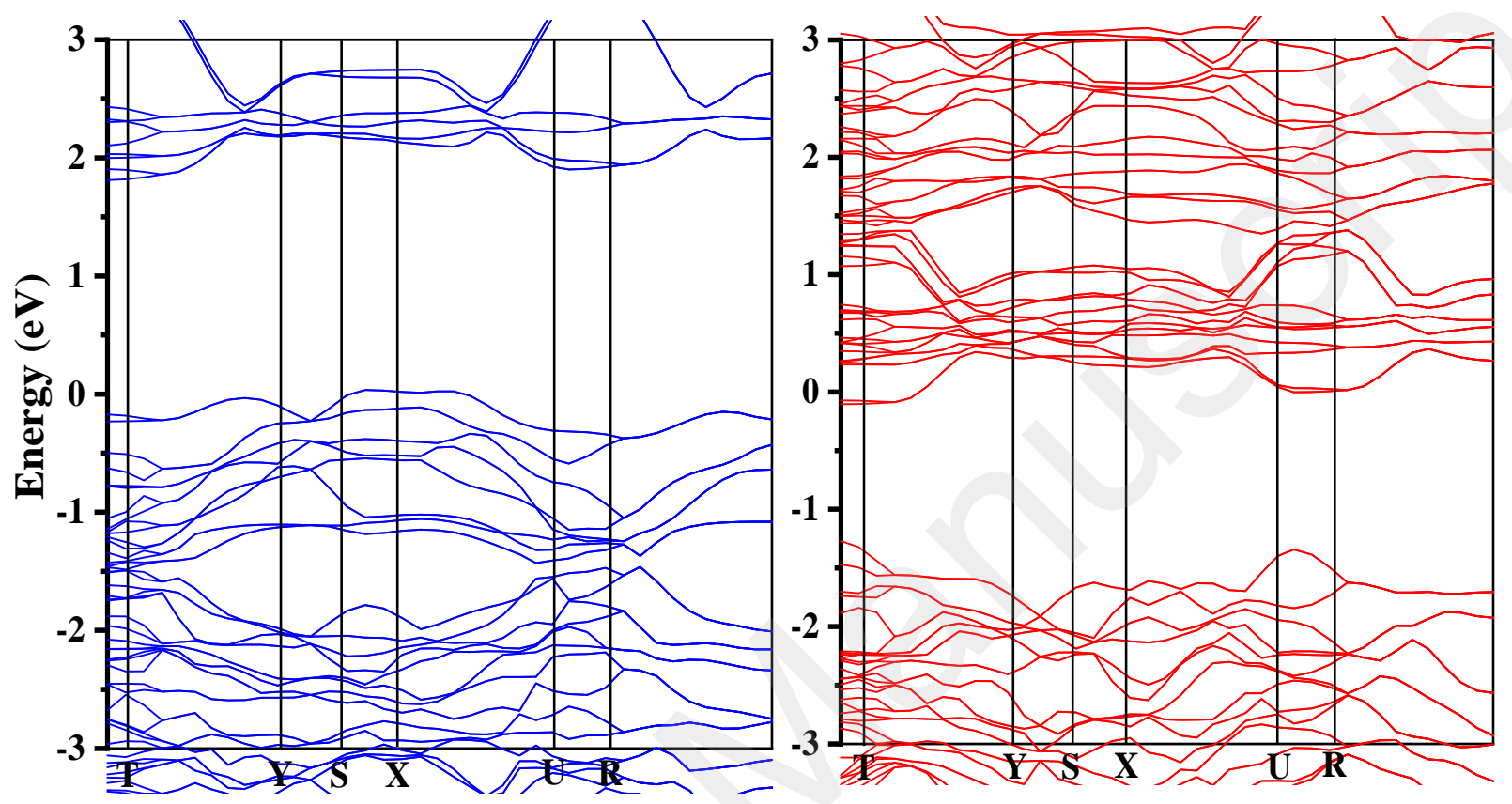
Figure 6
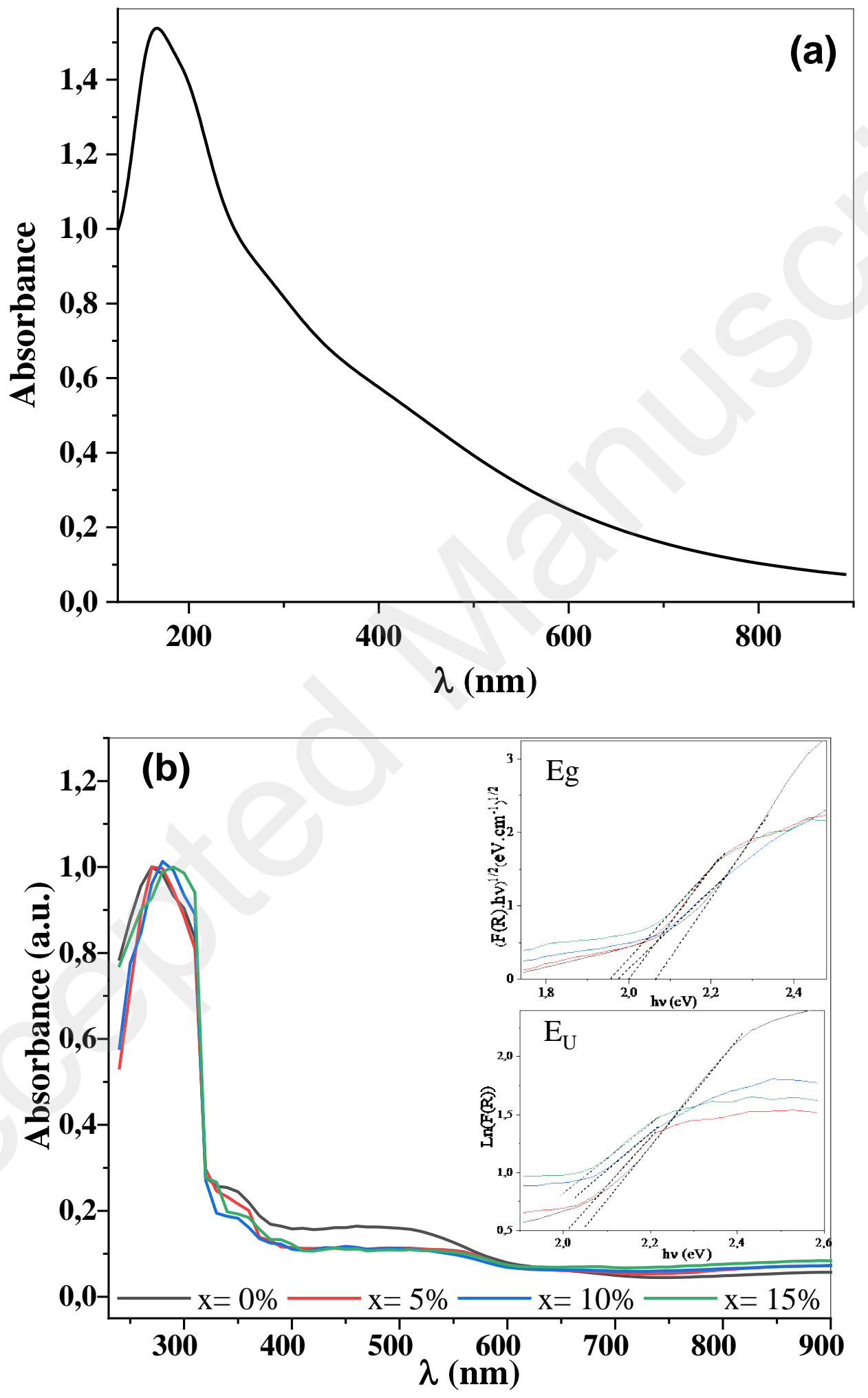
Figure 7

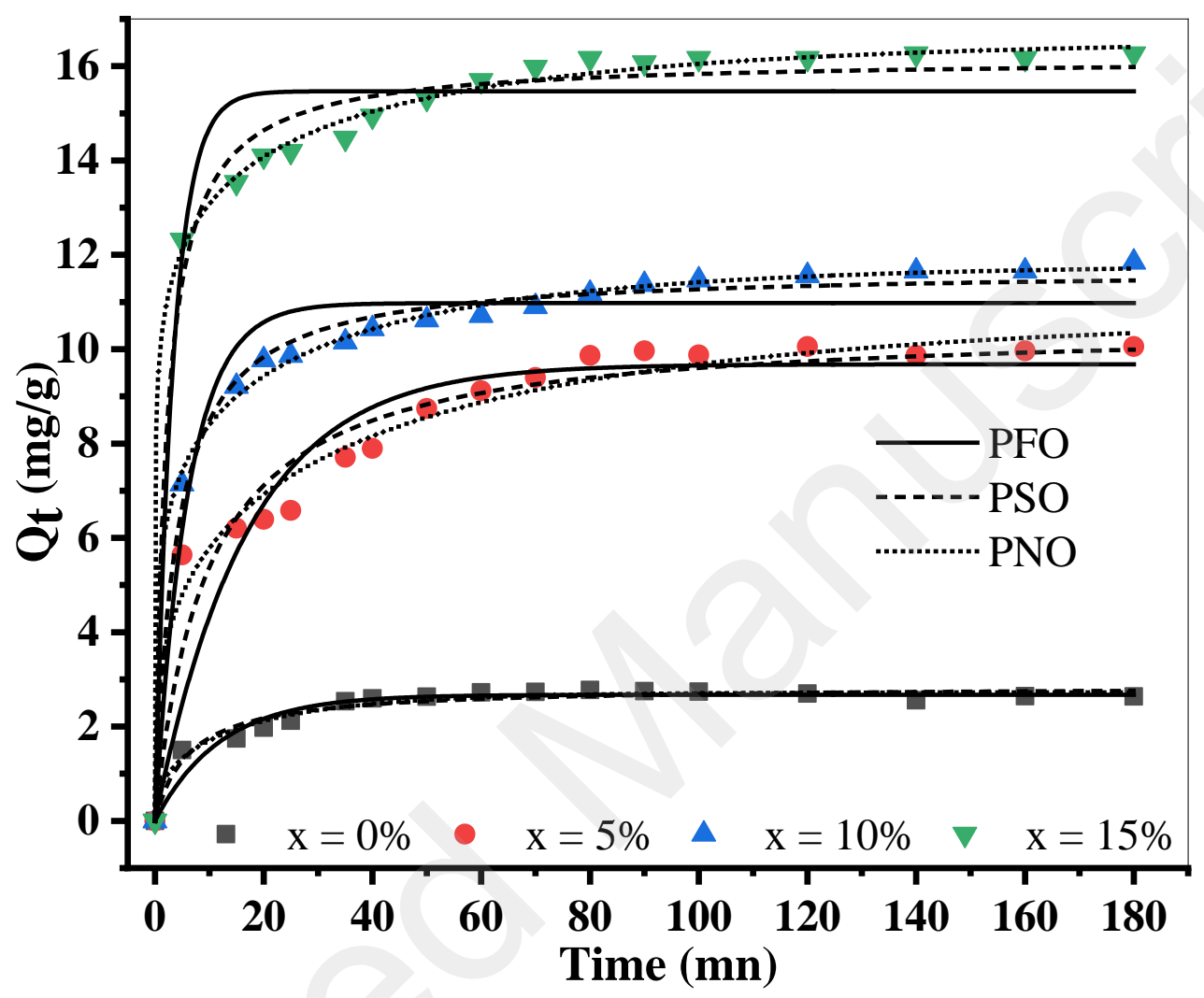


Figure 8
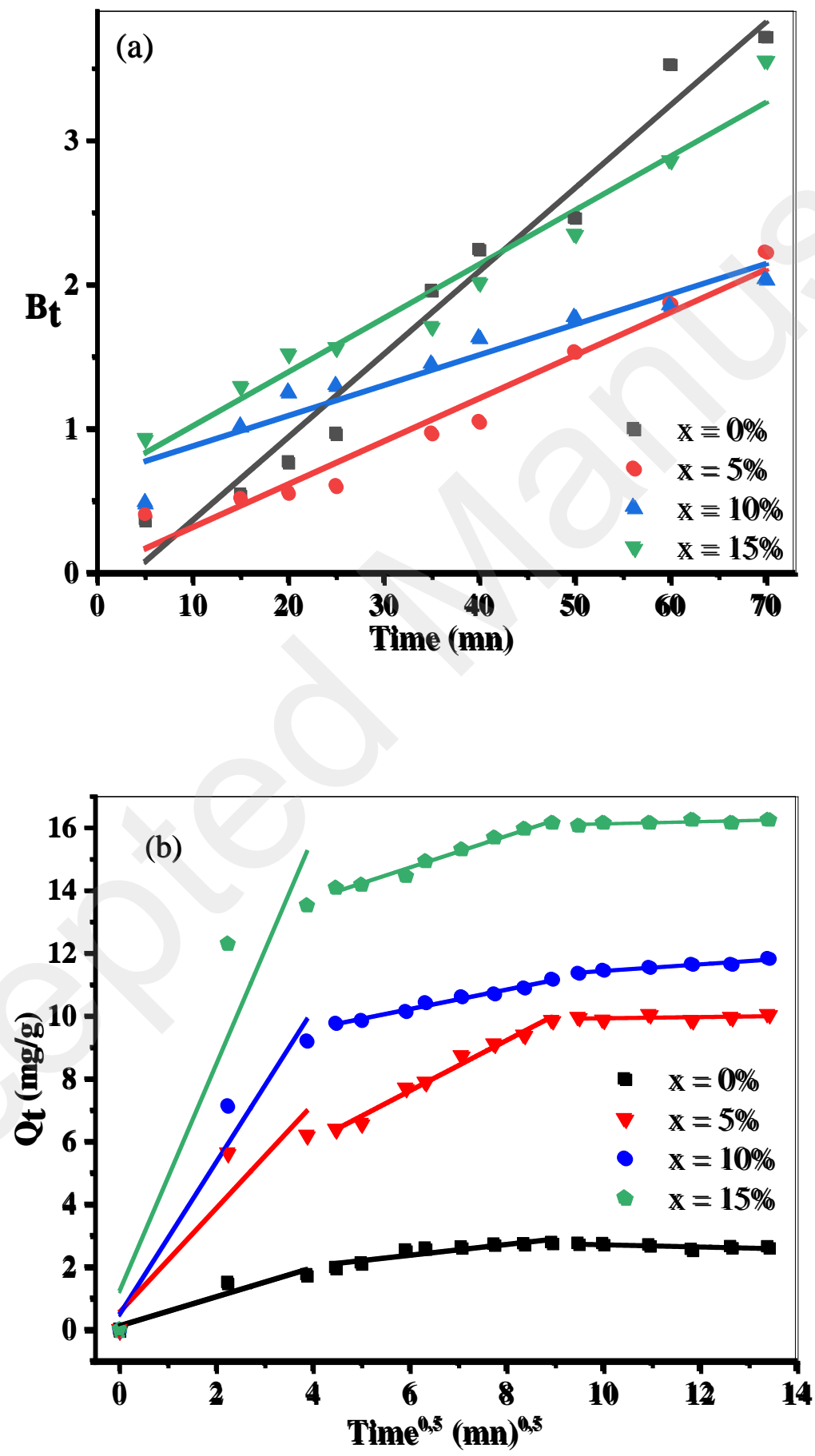
Figure 9

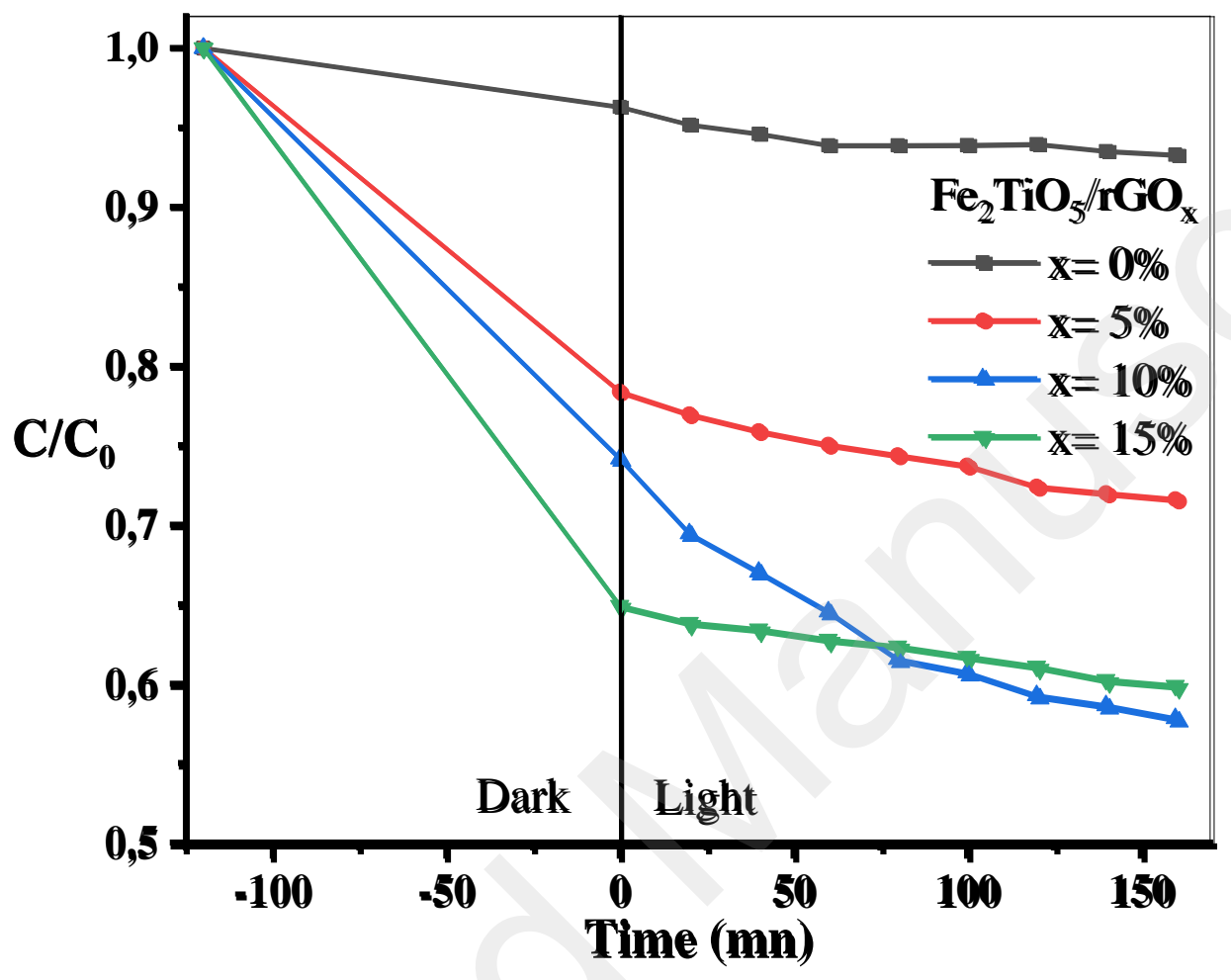


Figure 10

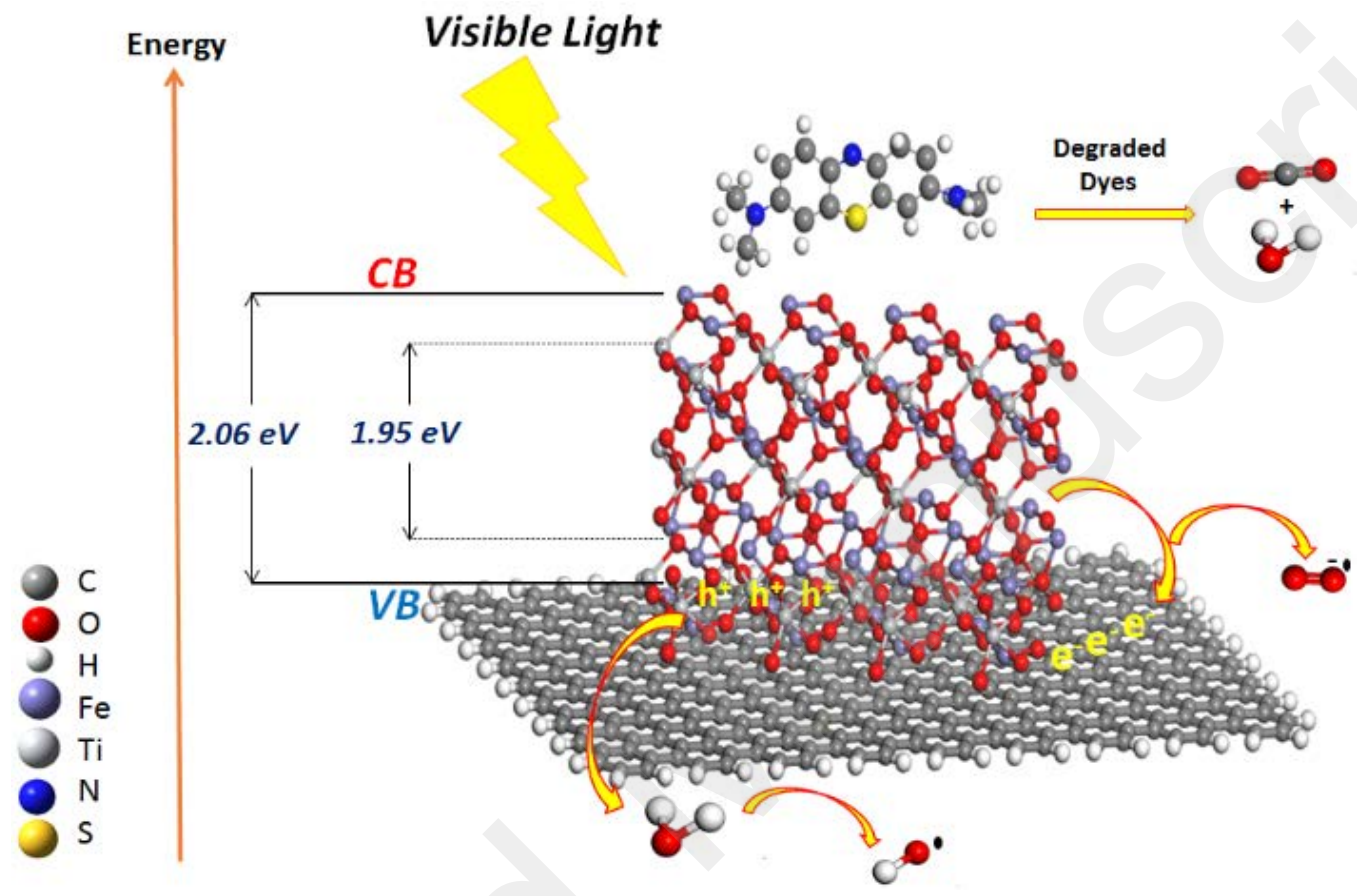


Table 1: Lattice parameters, grain seizes, microconstraints and dislocation densities of $\mathrm{Fe}_{2} \mathrm{TiO}_{5} / \mathrm{rGO}_{\mathrm{x}}(\mathrm{x}=$ 0, 5, 10 and $15 \%)$

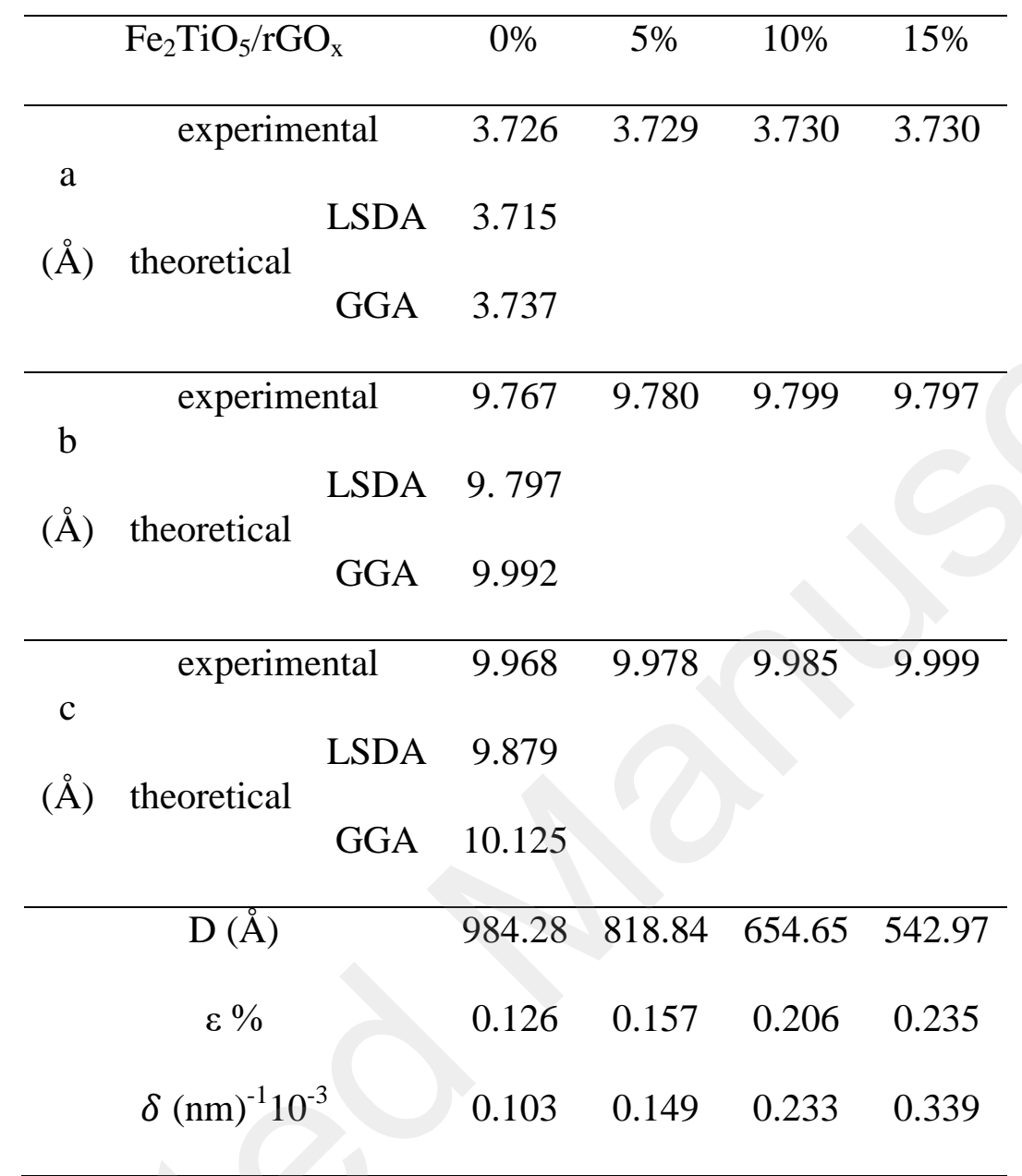


Table 2: Indirect and direct band gap energies and Urbach energy of $\mathrm{Fe}_{2} \mathrm{TiO}_{5} / \mathrm{rGO}_{\mathrm{x}}(\mathrm{x}=0,5$, 10 and 15\%)

\begin{tabular}{ccccccc}
\hline $\mathrm{Fe}_{2} \mathrm{TiO}_{5} / \mathrm{rGO}_{\mathrm{x}}$ & \multicolumn{3}{c}{$\mathrm{x}=0 \%$} & $\mathrm{x}=5 \%$ & $\mathrm{x}=10 \%$ & $\mathrm{x}=15 \%$ \\
\cline { 2 - 5 } & $\mathrm{Exp}$ & LSDA & GGA & & & \\
\hline Indirect band & 2.06 & 1.81 & 188 & 2.00 & 1.97 & 1.95 \\
Direct band & 2.26 & 198 & 207 & 2.07 & 2.05 & 2.02 \\
Urbach & & 216 & & 239 & 313 & 333 \\
\hline
\end{tabular}


Table 3 Modeling results of adsorption kinetics of $\mathrm{BM}$ on $\mathrm{Fe}_{2} \mathrm{TiO}_{5} / \mathrm{rGO}_{\mathrm{x}}$

\begin{tabular}{|c|c|c|c|c|c|c|c|c|c|c|c|}
\hline \multirow{3}{*}{$\begin{array}{l}\mathrm{Fe}_{2} \mathrm{TiO} \\
{ }_{5} / \mathrm{rGO}_{\mathrm{x}}\end{array}$} & \multirow{3}{*}{$\begin{array}{l}\mathrm{Q}_{\mathrm{e}} \text { exp. } \\
(\mathrm{mg} / \mathrm{g})\end{array}$} & \multicolumn{10}{|c|}{ Model } \\
\hline & & \multicolumn{3}{|c|}{ PFO } & \multicolumn{3}{|c|}{ PSO } & \multicolumn{4}{|c|}{$\mathrm{Pn}^{\text {th }} \mathrm{O}$} \\
\hline & & $\mathrm{K}_{1}$ & $\mathrm{Q}_{\mathrm{e}}$ & $\mathrm{R}^{2}$ & $\mathrm{~K}_{2}$ & $\mathrm{Q}_{\mathrm{e}}$ & $\mathrm{R}^{2}$ & $\mathrm{~K}_{\mathrm{n}}$ & $\mathrm{Q}_{\mathrm{e}}$ & $n$ & $\mathrm{R}^{2}$ \\
\hline 0 & 2.63 & 0.133 & 2.67 & 0.937 & 0.05 & 2.85 & 0.957 & 0.04 & 2.72 & 0.425 & 0.973 \\
\hline 5 & 10.06 & 0.059 & 9.68 & 0.875 & 0.01 & 10.5 & 0.935 & 0.01 & 10.69 & 0.284 & 0.976 \\
\hline 10 & 11.84 & 0.176 & 10.97 & 0.947 & 0.02 & 11.6 & 0.991 & 0.01 & 11.78 & 0.193 & 0.998 \\
\hline 15 & 16.26 & 0.301 & 15.46 & 0.951 & 0.03 & 16.1 & 0.985 & 0.01 & 16.55 & 0.119 & 0.997 \\
\hline
\end{tabular}


Table 4: Boyd and Webber (pore-diffusion) plots fit parameters

\begin{tabular}{lcccccc}
\hline & \multicolumn{5}{c}{ Model } \\
\cline { 2 - 7 } & \multicolumn{5}{c}{ Webber model } & \multicolumn{3}{c}{ Boyd plot } \\
\hline $\mathrm{Fe}_{2} \mathrm{TiO}_{5}$ & $\mathrm{k}_{\mathrm{I}} \mathrm{D}_{1}$ & $\mathrm{R}^{2}$ & $\mathrm{k}_{\mathrm{I}} \mathrm{D}_{1}$ & $\mathrm{R}^{2}$ & Intercept & $\mathrm{R}^{2}$ \\
$\mathrm{x}=0 \%$ & 0.464 & 0.909 & 0.172 & 0.833 & -0.206 & 0.970 \\
$\mathrm{x}=5 \%$ & 1.656 & 0.881 & 0.804 & 0.984 & 0.022 & 0.959 \\
$\mathrm{x}=10 \%$ & 2.426 & 0.953 & 0.310 & 0.983 & 0.672 & 0.913 \\
$\mathrm{x}=15 \%$ & 3.613 & 0.881 & 0.503 & 0.982 & 0.649 & 0.959 \\
& & & & & & \\
\hline
\end{tabular}

